\title{
THE IMPACT OF PLANT-LEVEL RESOURCE ALLOCATIONS AND TECHNICAL PROGRESS ON U.S. MACROECONOMIC GROWTH
}

\author{
by \\ Amil Petrin * \\ University of Minnesota and NBER \\ T. Kirk White * \\ U.S. Department of Agriculture \\ Jerome P. Reiter * \\ Duke University
}

CES 09-43 December, 2009

The research program of the Center for Economic Studies (CES) produces a wide range of economic analyses to improve the statistical programs of the U.S. Census Bureau. Many of these analyses take the form of CES research papers. The papers have not undergone the review accorded Census Bureau publications and no endorsement should be inferred. Any opinions and conclusions expressed herein are those of the author(s) and do not necessarily represent the views of the U.S. Census Bureau. All results have been reviewed to ensure that no confidential information is disclosed. Republication in whole or part must be cleared with the authors.

To obtain information about the series, see www.ces.census.gov or contact Cheryl Grim, Editor, Discussion Papers, U.S. Census Bureau, Center for Economic Studies 2K130B, 4600 Silver Hill Road, Washington, DC 20233, Cheryl.Ann.Grim@census.gov. 


\begin{abstract}
We build up from the plant level an "aggregate(d) Solow residual" by estimating every U.S. manufacturing plant's contribution to the change in aggregate final demand between 1976 and 1996. We decompose these contributions into plant-level resource reallocations and plant-level technical efficiency changes. We allow for 459 different production technologies, one for each 4digit SIC code. Our framework uses the Petrin and Levinsohn (2008) definition of aggregate productivity growth, which aggregates plant-level changes to changes in aggregate final demand in the presence of imperfect competition and other distortions and frictions. On average, we find that aggregate reallocation made a larger contribution than aggregate technical efficiency growth. Our estimates of the contribution of reallocation range from 1:7\% to2:1\% per year, while our estimates of the average contribution of aggregate technical efficiency growth range from $0: 2 \%$ to $0: 6 \%$ per year. In terms of cyclicality, the aggregate technical efficiency component has a standard deviation that is roughly $50 \%$ to $100 \%$ larger than that of aggregate total reallocation, pointing to an important role for technical efficiency in macroeconomic fluctuations. Aggregate reallocation is negative in only 3 of the 20 years of our sample, suggesting that the movement of inputs to more highly valued activities on average plays a stabilizing role in manufacturing growth.
\end{abstract}

JEL codes: E32, L6, O47

Key words: Macroeconomic Fluctuations; Aggregate Productivity Growth; Reallocation; Technical Efficiency

* The research in this paper was conducted while the authors were Special Sworn Status researchers of the U.S. Census Bureau at the Triangle Census Research Data Center. Any opinions and conclusions expressed herein are those of the authors and do not necessarily represent the views of the U.S. Census Bureau or of the U.S. Department of Agriculture. All results have been reviewed to ensure that no confidential information is disclosed. We thank Susanto Basu, John Fernald, John Haltiwanger, Stephanie Schmitt-Grohe, Chad Syverson, and other participants in the International Industrial Organization Conference, the Midwest Macro Meetings, the 2009 Minnesota Applied Micro Workshop, the RED Mini-Conference on Sources of Business Cycle Fluctuations, the 2009 NBER Productivity Potpourri Workshop, the Jornadas de Economia Industrial conference in Vigo, the Census Bureau's Center for Economic Studies Seminar, and the Cornell Census Research Data Center Conference for comments. 


\section{Introduction}

What are the micro-level components of aggregate productivity growth and macroeconomic fluctuations? Aggregate final demand can increase without an increase in input use if plants become more technically efficient, perhaps by inventing new and better methods of production or by learning to imitate other better-performing plants. Alternatively, final demand increases without more input use when the invisible hand of the market reallocates an input to a more valued market activity.

In this paper we construct estimates of every U.S. Manufacturing plant's contribution to changes in aggregate final demand holding input use constant between 1976 and $1996 .{ }^{1}$ We then decompose this aggregate(d) Solow residual into a component arising from the aggregated impacts of resource reallocation and one related to aggregated technical efficiency changes. In doing so we estimate production functions separately for each of our 459 4-digit SIC industries and compare results across several different production function estimators, including Ordinary Least Squares, Levinsohn and Petrin (2003, LP), and the Wooldridge (2005) variant of the LP estimator. Our findings have important implications for the sources of growth and macroeconomic fluctuations at business cycle frequencies. Specifically, we show that aggregate reallocation and aggregate technical efficiency both play important roles in growth, and that most of the volatility in aggregate productivity growth over this period was due to variation in the growth rate of technical efficiency.

Our definition of aggregate productivity growth (APG) determines the relevant measurements for calculation of the plant-level contributions to reallocation and technical efficiency. We adopt the one from Petrin and Levinsohn (2008), which we call PL-APG. It is defined so that changes at the micro-level in reallocation and technical efficiency, when aggregated across all plants, equal the aggregate change in final demand holding primary inputs

\footnotetext{
${ }^{1}$ For value-added production functions, we provide estimates for 1976 to 1999 . We had to stop in 1996 for the gross-output specification because we did not have a deflator for energy inputs after 1996. See tables 5-6 and A5-A6 for our results from the value-added specification.
} 
constant. Specifically, aggregate technical efficiency is the Domar-weighted sum of plant-level growth rates in technical efficiency. Aggregate reallocation tracks the movement of inputs across plants with different wedges between their marginal revenue and marginal cost.

The two stories - technical efficiency and reallocation - are not mutually exclusive. Both may be important causes of aggregate productivity growth, both at business cycle frequencies and in the long run. On reallocation, to the extent that an economy is not perfectly frictionless or perfectly competitive, policies that reduce these frictions or increase competition may have large effects on aggregate productivity growth via reallocation. We estimate aggregate reallocation and we decompose it into terms related to production workers, non-production workers, capital, and intermediate inputs to try to understand which frictions are most important in U.S. manufacturing.

Over the period 1976-1996 we find that reallocation plays an important and stabilizing role in the aggregate productivity growth of manufacturing, which grew at an average annual rate of $2.2 \%$ with a standard deviation of $3.7 \%$. Reallocation's contribution to this growth is positive in all but 3 years, on average accounting for more than half of aggregate productivity growth $(1.7 \%$ to $2.2 \%$ per year, depending on the production function estimator). The volatility in the reallocation term is relatively small, with the standard deviation of $1.1 \%$ to $1.7 \%$. Technical efficiency growth was smaller on average ( $0.2 \%$ to $0.6 \%$ per year), but it was also responsible for most of the volatility in aggregate productivity growth, as its standard deviation was $2.6 \%$ to $3.0 \%$.

The result that aggregate reallocation makes relatively stable and mostly positive contributions to aggregate productivity growth is robust to a variety of estimators of plant-level productivity, and has been found in Chilean and Colombian data as well. This result makes economic sense, as Petrin and Levinsohn (2008) show that in the presence of imperfect competition, frictions in input markets, or fixed costs, reallocation of resources can contribute to aggregate productivity growth. Furthermore, we expect that any market populated by profit-maximizing firms will have resources reallocating on average towards uses with higher marginal products. 
Our results are useful for determining which of the many theoretical growth models with adjustment frictions appear consistent with U.S. manufacturing. They also shed light on the precise meaning of counterfactuals that take the U.S. as a "frictions benchmark" and then ask how much output would increase if a country were able to achieve the U.S. level of frictions. For example, Hsieh and Klenow (2007) ask what the impact for growth would be in China and India if capital and labor were reallocated to reflect the level of frictions that we see in U.S. manufacturing industries. Our findings suggest that the U.S. benchmark is one with small gains from further reallocation of non-production and production workers, and substantially larger gains from the reallocation of capital.

While the finding of a positive contribution of aggregate reallocation makes economic sense, it is in contrast to estimates of productivity growth due to reallocation as defined by other measures, such as in Baily, Hulten, and Campbell (1992, BHC hereafter). These indices define APG exclusively as the change in the average of the plant-level technical efficiency shocks, and thus do not aggregate plant-level changes in inputs and technical efficiency to changes in aggregate value added. Petrin and Levinsohn (2008) explain how the BHC index is related to PL-APG, and how it is not. When we estimate aggregate productivity growth and reallocation as defined by the BHC index, we find that the volatility of growth due to reallocation is enormous: the standard deviation of the annual rate is as high as 7.8 percentage points - more than 4 times the volatility of the P-L measure of reallocation. In many years, the contribution of BHC-measured reallocation is both large (in absolute value) and negative, sometimes indicating a decline of more than $20 \%$ in a single year. ${ }^{2}$ We find these results are robust to a variety of production function estimators, suggesting the way one defines aggregate productivity growth can have a substantial impact on how one interprets the roles of technical efficiency and reallocation in any economy. These differences between PL-APG-measured reallocation and

\footnotetext{
${ }^{2}$ When we use a value-added specification of the production function, we find that the $\mathrm{BHC}$ reallocation index shows even greater volatility, with a standard deviation of 15.2 percentage points, and a maximum single-year decline for more than $30 \%$.
} 
BHC-measured reallocation for U.S. manufacturing data are also consistent with findings for Chilean, Colombian, and Japanese micro data.

In section 2 we discuss the theory in continuous time. Section 3 describes the discrete-time approximation. Section 4 describes the estimation. Section

5 describes the data. Readers interested only in the results can skip to section 6. Section 7 discusses the implications of our results for models of business cycle fluctuations. Section 8 concludes.

\section{Theory}

Measuring aggregate productivity growth is an old and honored tradition in macroeconomics, and there is an enormous theoretical and empirical literature devoted to it. Solow (1957) shows that in a perfectly competitive economy with an aggregate production function and without distortions, the residual measures both aggregate technology change and aggregate productivity change. Hulten (1978) shows that if one estimates technological change from disaggregated data and then aggregates, under perfect competition Solow's result still holds. Hall (1988) and Hall (1990) show that the estimate of technological change is affected by imperfect competition. More recently, Basu and Fernald (2002) study an economy with markups, showing that aggregate productivity growth and technological progress differ, and that there is a role for reallocation of resources in increasing aggregate final demand.

Petrin and Levinsohn (2008) extend Basu and Fernald to plant-level data, showing how to aggregate changes in plant-level technical efficiency and changes in resource allocations across plants to changes in aggregate final demand. The linkage provides a theoretical basis for decomposing changes in aggregate final demand holding primary inputs constant - which they define as aggregate productivity growth - into the contribution of technological progress (or "technical efficiency") and several terms that measure the contribution of the reallocation of inputs across plants, one for every input. In this paper we provide the first application of the Petrin and Levinsohn (2008) measure to U.S. data. 
We follow the discussion from Petrin and Levinsohn (2008, P-L hereafter). We operate in continuous time, and assume the production side of the economy has at any time at most $\mathrm{N}$ plants. While it is not difficult to extend the framework to multi-product plants, we assume for transparency all plants are single product plants. We let each plant $i$ 's production technology be written as

$$
Q^{i}\left(X_{i}, M_{i}, \omega_{i}\right)
$$

where $X_{i}=\left(X_{i 1}, \ldots, X_{i K}\right)$ is the vector of $\mathrm{K}$ primary input amounts used at plant $i, M_{i}=\left(M_{i 1}, \ldots, M_{i J}\right)$ is the vector giving the amount of each plant $j$ 's output used as an intermediate input at plant $i$, and $\omega_{i}$ is the level of plant $i$ 's technical efficiency. Primary inputs may include several types of different labor and capital, and any of the $\mathrm{N}$ products may potentially be used as an input in production somewhere in the economy.

We use $F_{i}$ to denote the sum of all fixed and sunk costs that are paid by plant $i$. We normalize these costs to the equivalent of the forgone output and deduct them directly from the production function, letting

$$
Q_{i}=Q^{i}\left(X_{i}, M_{i}, \omega_{i}\right)-F_{i}
$$

The total amount of output from plant $i$ that goes to final demand $Y_{i}$ is then

$$
Y_{i}=Q_{i}-\sum_{j} M_{j i}
$$

where $\sum_{j} M_{j i}$ is the total amount of $i$ 's output that serves as intermediate input within the plant and at other plants. The differential in levels is

$$
d Y_{i}=d Q_{i}-\sum_{j} d M_{j i}
$$

$P_{i}$ denotes the price of plant i's output, and thus $\sum_{i} P_{i} d Y_{i}$ is equal to the change in final demand.

P-L defines aggregate productivity growth as the difference between the change in aggregate final demand and the change in aggregate costs:

$$
P L_{L E V E L} \equiv \sum_{i} P_{i} d Y_{i}-\sum_{i} \sum_{k} W_{i k} d X_{i k}
$$


where $W_{i k}$ equals the unit cost of the kth primary input and $d X_{i k}$ is the change in the use of that primary input at plant $i$. Converting (3) to growth rates we have:

$$
P L_{G R O W T H}=\sum_{i} D_{i} d \ln Y_{i} *-\sum_{i} \sum_{k} s_{i k} d \ln X_{i k}
$$

where $D_{i}=\frac{P_{i} Q_{i}}{\sum_{i=1}^{N} P_{i} Y_{i}}$ is the Domar (1961) weight, $d \ln Y_{i} *=\frac{d Y_{i}}{Q_{i}}$ is the growth rate of $i$ 's output going to final demand, and

$$
s_{i k}=\frac{W_{i k} X_{i k}}{\sum_{i=1}^{N} P_{i} Y_{i}}
$$

We do not observe in the data the amount of a plant's output that ultimately goes to final demand. However, the Growth Accounting Identity shows that aggregate final demand is equal to aggregate value added:

$$
\sum_{i} D_{i} d \ln Y_{i} *=\sum_{i} D_{i}^{v} d \ln V A_{i}
$$

with value added

$$
V A_{i}=P_{i} Q_{i}-\sum_{j} P_{j} M_{i j}
$$

and the Domar weight equal to the plant's share of value added $D_{i}^{v}=\frac{V A_{i}}{\sum_{i} V A_{i}}$. We then replace the first term in (3) and calculate aggregate productivity growth as

$$
P L_{G R O W T H}=\sum_{i} D_{i}^{v} d \ln V A_{i}-\sum_{i} \sum_{k} s_{i k} d \ln X_{i k}
$$

with the cost share for the $k t h$ primary input now given as

$$
s_{i k}=\frac{W_{i k} X_{i k}}{\sum_{i} V A_{i}}
$$

Lemma 1 in P-L shows when $Q_{i}$ is differentiable that equation (3) can be decomposed as follows:

$$
\sum_{i} \sum_{k}\left(P_{i} \frac{\partial Q_{i}}{\partial X_{i k}}-W_{i k}\right) d X_{i k}+\sum_{i} \sum_{j}\left(P_{i} \frac{\partial Q_{i}}{\partial M_{i j}}-P_{j}\right) d M_{i j}-\sum_{i} P_{i} d F_{i}+\sum_{i} P_{i} d \omega_{i},
$$


where $\frac{\partial Q}{\partial X_{i k}}$ and $\frac{\partial Q}{\partial M_{i j}}$ are the partial derivatives of the output production function with respect to the $k t h$ primary input and the $j t h$ intermediate input respectively, $d M_{i j}$ is the change in intermediate input $j$ at plant $i, d F_{i}$ is the change in fixed and sunk costs, and $d \omega_{i}$ is the change in "net output" at plant $i$, defined as the output remaining after the contribution of both primary and intermediate inputs at plant $i$ have been deducted:

$$
d \omega_{i}=d Q_{i}-\sum_{k} \frac{\partial Q_{i}}{\partial X_{i k}} d X_{i k}-\sum_{j} \frac{\partial Q_{i}}{\partial M_{i j}} d M_{i j}
$$

Equation (9) shows that under this definition of aggregate productivity growth, if at every firm every marginal product is equated with every marginal cost, then further reallocation cannot increase growth, as all allocative efficiency gains have been achieved. However, if there is market power (i.e. markups) or frictions such as adjustment costs or taxes, or other characteristics of the economy that lead to a divergence between the marginal product and the marginal cost, then the reallocation of inputs can increase aggregate productivity growth. This reallocation effect is captured in the first two summation terms in (9).

Equation (9) can be rewritten in growth rates as:

$$
\sum_{i} D_{i} \sum_{k}\left(\varepsilon_{i k}-c_{i k}\right) d \ln X_{i k}+\sum_{i} D_{i} \sum_{j}\left(\varepsilon_{i j}-c_{i j}\right) d \ln M_{i j}-\sum_{i} D_{i} d \ln F_{i}+\sum_{i} D_{i} d \ln \omega_{i},
$$

where $D_{i}$ is the Domar weight, $\varepsilon_{i k}$ and $\varepsilon_{i j}$ are the elasticities of output with respect to primary and intermediate inputs, $c_{i k}=\frac{W_{i k} X_{i k}}{P_{i} Q_{i}}$ and $c_{i j}=$ $\frac{P_{j} M_{i j}}{P_{i} Q_{i}}$ are the respective plant-specific revenue shares for both primary and intermediate inputs, and $d \ln F_{i}$ and $d \ln \omega_{i}$ denoting the growth rates in fixed costs and technical efficiency, with the base given by $Q_{i}$.

If a value added production function exists (e.g., see Bruno (1978)), then we can express the decomposition as ${ }^{3}$

$\sum_{i} \sum_{k}\left(D_{i}^{v} \varepsilon_{i k}^{v}-s_{i k}\right) d \ln X_{i k}+\sum_{i} \sum_{j}\left(D_{i}^{v} \varepsilon_{i j}^{v}-s_{i j}\right) d \ln M_{i j}-\sum_{i} D_{i}^{v} d \ln F_{i}^{v}+\sum_{i} D_{i}^{v} d \ln \omega_{i}^{v}$,

\footnotetext{
${ }^{3} \mathrm{~A}$ sufficient condition is that the intermediate inputs are separable in the gross output production function.
} 
where the elasticities are now those for the value added production function, which can be shown to equal the elasticities from the gross output production function divided by one minus the ratio of intermediate expenditures to revenues:

$$
\varepsilon_{i j}^{v}=\frac{\varepsilon_{i j}}{1-\sum_{j} c_{i j}}
$$

$\ln F^{v}$ denotes the growth rate in fixed costs divided by one minus the ratio of intermediate inputs expenditures to revenues. The value added technical efficiency shock is derived from the value added production function, which can be expressed as

$$
\ln \omega_{i}^{v}=\ln \left(V A_{i}\right)-\sum_{k} \varepsilon_{i k}^{v} \ln X_{i k}
$$

with intercept $\beta_{0}^{v} \cdot{ }^{4}$ The relationship between the value added technical efficiency shock and the gross output production function technical efficiency shock is

$$
\ln \omega_{i}^{v}=\frac{\ln \omega_{i}}{1-\sum_{j} c_{i j}} .
$$

We now discuss implementation of this index with discrete time data.

\section{Discrete Time Approximation}

The theory says that we can compute an approximation to PL-APG directly from plant-level data without having to estimate production functions. However, up to this point all of the equations that we have considered have been written in continuous time, and the data we observe has been aggregated to discrete intervals. We use Tornquist-Divisia approximations for all of our calculations. For example, for equation (7), we calculate growth as

$$
P L_{G, t}=\sum_{i} \bar{D}_{i t}^{v} \Delta \ln V A_{i t}-\sum_{i} \sum_{k} \bar{s}_{i k t} \Delta \ln X_{i k t}
$$

\footnotetext{
${ }^{4}$ If the elasticity of output with respect to each intermediate input is not equal to the intermediate's revenue share, then the estimated residual will include additional terms related to the intermediates.
} 
where $\bar{D}_{i t}^{v}$ is the average of plant $i$ 's value-added share weights from period t- 1 to period t, $\Delta$ is the first difference operator from $t-1$ to $t, \bar{s}_{i k t}$ is the average across the two periods of plant $i$ 's expenditures for the kth primary input as a share of aggregate value-added.

We do need estimates of production function parameters and residuals to estimate the components of the decomposition. Equation (9) can be estimated in discrete-time by:

$$
\begin{aligned}
P L_{G, t}= & \sum_{i} \bar{D}_{i t} \sum_{k}\left(\varepsilon_{i k}-\bar{c}_{i k t}\right) \Delta \ln X_{i k t}+\sum_{i} \bar{D}_{i t} \sum_{j}\left(\varepsilon_{i j}-\bar{c}_{i j t}\right) \Delta \ln M_{i j t} \\
& -\sum_{i} \bar{D}_{i t} \Delta \ln F_{i t}+\sum_{i} \bar{D}_{i t} \Delta \ln \omega_{i t},
\end{aligned}
$$

where again bars over variables denote two-period averages and $\Delta$ is the firstdifference operator. We estimate the production function parameters in logs and use them as estimates for $\varepsilon_{i k}$ and $\varepsilon_{i j}$. For the growth rate in plant-level technical efficiency, we use the posited functional form for the production function to calculate the residuals, and then take the first difference. For example, if we assume a Cobb-Douglas production function, we would take first differences of an estimate of:

$$
\ln \omega_{i}=\ln Q_{i}-\left(\sum_{k} \varepsilon_{i k} \ln X_{i k}+\sum_{j} \varepsilon_{i j} \ln M_{i j}\right)
$$

We do not observe changes in fixed costs in our data directly, but we can infer the aggregate change as the difference between PL growth and the reallocation and technical efficiency terms. ${ }^{5}$

If intermediate inputs are separable in the production function then one can approximate the decomposition using a value added production function to construct estimates of the elasticities and changes in technical efficiency. In this case the decomposition is given as

$$
\begin{aligned}
P L_{G, t}= & \sum_{i} \sum_{k}\left(\bar{D}^{v}\right. \\
& \left.-\varepsilon_{i k}^{v}-\bar{s}_{i k t}\right) \Delta \ln X_{i k t}+\sum_{i} \sum_{j}\left(\bar{D}_{i t}^{v} \varepsilon_{i j}^{v}-\bar{s}_{i j t}\right) \Delta \ln M_{i j t} \\
& -\sum_{i t} \Delta \ln F_{i t}^{v}+\sum_{i} \bar{D}_{i t}^{v} \Delta \ln \omega_{i t}^{v},
\end{aligned}
$$

\footnotetext{
${ }^{5}$ Our fixed costs residual term will also include discrete-time approximation error. See Appendix D for a derivation. Empirically, this discrete-time approximation error turns out to be an important part of our "fixed costs" term.
} 
with the value added residual calculated as

$$
\ln \omega_{i}^{v}+\sum_{j}\left(\varepsilon_{i j}-c_{i j t}\right) \ln M_{i j t}=\ln V A_{i}-\left(\sum_{k} \varepsilon_{i k}^{v} \ln X_{i k}\right) .
$$

Note that we have explicitly included in the residual the terms related to the intermediate inputs, which will be non-zero if the elasticity of output is not equal to the ratio of expenditure on the input to total revenues for one or more intermediate inputs. ${ }^{6}$ We now turn to the data and estimation.

\section{Production Function and Technical Efficiency Estimation}

One major advantage of PL-APG and its decomposition in (11) is that many of the components are either directly observed or easy to estimate using standard plant-level data sets. Both Domar weights $D_{i t}$ and $D_{i t}^{v}$ are measurable as $P_{i} Q_{i}$ and $V A_{i}$ are observed for every plant-year. The shares in (11) are typically observed for all inputs but capital because plants report expenditures on their inputs. Finally, the plant-level data can also be used to estimate the parameters and technical efficiency terms for both gross output and value added production functions.

We estimate both the value added and the gross output specifications and their associated decompositions. While the value-added specification is less general than the gross output approach, it is more widely used in macroeconomics, perhaps because it is more natural for looking at macroeconomic aggregates. A comparison of the two shows the empirical impact of assuming separability of intermediate inputs, the restriction that makes the value added production function a special case of the gross output production function. We also compare the estimated technical efficiency residuals across the two approaches - properly adjusted as in (14) - to see if differences

\footnotetext{
${ }^{6}$ The additional term in the residual arises because value added is defined by subtracting the expenditures on intermediate inputs. When the revenue share equals the elasticity, the intermediate terms cancel out in the move from the gross output production function to the value added production function.
} 
between output elasticities and revenue shares for intermediate inputs are important in confounding technical efficiency.

Our definition of plant-level double deflated value added is given by

$$
V A_{i t}^{D D}=\frac{P_{i t} Q_{i t}}{P_{t}}-\frac{P_{i M t} M_{i t}}{P_{t}^{M}}-\frac{P_{i E t} E_{i t}}{P_{t}^{E}}
$$

where we deflate expenditures on materials (M) and energy (E) using a 4digit industry price indexes for materials $\left(P_{t}^{M}\right)$ and energy $\left(P_{t}^{E}\right)$. In a perfect world we would like our output measure to be $Q_{i t}$, the quantity of output. While we observe every plant's nominal value of total shipments - $P_{i t} Q_{i t}$ for most plants we do not have separate observations on price and quantity. Suppose for the moment that there are no intermediate inputs. If we relate changes in $\ln \left(P_{i t} Q_{i t}\right)$ to changes in inputs, $\ln P_{i t}$ enters as measurement error. It will bias the estimated coefficients if changes in price are correlated with changes in inputs used. For example, if demand is downward sloping and a plant increases output (and inputs) then the fall in price will be associated with an increase in inputs (and vice versa), and coefficient estimates will be biased.

We deflate nominal gross output by a 4-digit industry price index for shipments, denoted $P_{s}$ for time period $s$, so that the measurement error in output is now given by the log ratio of the plant's output price to average industry price as given by the index. Continuing to abstract from intermediate inputs, our dependent variable in the regressions becomes

$$
\ln \frac{P_{i t} Q_{i t}}{P_{t}}=\ln Q_{i t}+\ln P_{i t}-\ln P_{t},
$$

and we think that it is less likely that the relative price $\ln P_{i t}-\ln P_{t}$ will be correlated with input levels.

Unobserved prices also potentially confound the estimate of plant-level technical efficiency. Again, if we continue to abstract from intermediate inputs, in terms of growth rates, the size of the price measurement error added to the growth in technical efficiency is

$$
\ln \left(\frac{P_{i t}}{P_{t}}\right)-\ln \left(\frac{P_{i, t-1}}{P_{t-1}}\right) .
$$


If the relative price of plant i's output to the 4-digit industry price index does not change, then unobserved prices add no error to the technical efficiency residual. Otherwise it is increasing in the relative change in price. ${ }^{7}$ In future work, we plan to assess the amount of measurement error associated with missing price data by linking the plant-level Census data to transaction prices from the Bureau of Labor Statistics Producer Price Index program. However, linking this price data is a large project, and is beyond the scope of the current paper.

Error also arises because intermediates in our data are treated as an aggregate and because the price deflator is likely to vary by plant. There is also an additional term in the technical efficiency residual unless intermediate inputs grow at the same rate as output (see Bruno (1978) or Basu and Fernald (1995)). Our comparison of the decompositions between the gross output and the value added case will shed light on the impact of these approximations.

Our gross output production function specification includes three primary inputs: production worker labor $\left(L^{P}\right)$, non-production worker labor $\left(L^{N P}\right)$, and capital $(\mathrm{K})$. We also have intermediate inputs, which includes the cost of parts and materials (M) and energy (E). ${ }^{8}$ Our value added specifications include just the three primary inputs as regressors. For production

\footnotetext{
${ }^{7}$ Foster, Haltiwanger, and Syverson (2008) (FHS) estimate both physical quantitybased productivity (similar to our equation 17) and revenue-based plant-level productivity for the small subset of manufacturing industries for which physical quantities and plant-level prices of output are available. They find that plant-level physical productivity shows more within-industry dispersion than plant-level revenue-based productivity because physical productivity is negatively correlated with plant-level prices. To the extent that their results generalize to all manufacturing industries, this suggests that revenuebased measures of productivity will have less within-industry dispersion than the physical quantity-based technical efficiency. We investigated using the same physical quantity data that FHS use. Unfortunately, this data is available only in quinquennial Census years, and only for certain products in certain industries.

${ }^{8}$ When we used the Levinsohn and Petrin (2003) estimator, we used energy as a proxy variable, and therefore did not estimate an output elasticity for energy. For the OLS and Wooldridge (2005) estimators, we included both materials and energy as separate variables in the production functions.
} 
workers we observe total number of hours at the plant. ${ }^{9}$ For non-production workers, we only observe number of bodies, so we abstract from utilization. For capital we use the real value of the total capital stock at the plant, constructed using the perpetual inventory method. Similarly, we are working to correct the stock for unobserved utilization rates. ${ }^{10}$ The data appendix contains more detailed descriptions of our measures.

We posit a Cobb-Douglas production function. We estimate production functions separately for each of our 459 4-digit SIC industries using the Levinsohn and Petrin (2003, LP) estimator. ${ }^{11}$

Given any estimator of production function coefficients our estimate of plant-level technical efficiency from the gross output specification is then

$$
\begin{aligned}
\ln \widehat{\omega}_{i t}=\ln \frac{P_{i t} Q_{i t}}{P_{j t}} & -\left(\widehat{\epsilon}_{j P} \ln L_{i t}^{P}+\widehat{\epsilon}_{j N P} \ln L_{i t}^{N P}+\widehat{\epsilon}_{j K} \ln K_{i t}\right. \\
& \left.+\widehat{\epsilon}_{j M} \ln M_{i t}+\widehat{\epsilon}_{j E} \ln E_{i t}\right)
\end{aligned}
$$

where $\widehat{\epsilon}_{j}$. denotes the estimated elasticities of output with respect to the inputs in 4-digit SIC industry $j$. Similarly, our estimate of technical efficiency for the value-added specification is given as

$$
\ln \widehat{\omega}_{i t}=\ln \left(V A_{i t}\right)-\left(\widehat{\epsilon}_{j P} \ln L_{i t}^{P}+\widehat{\epsilon}_{j N P} \ln L_{i t}^{N P}+\widehat{\epsilon}_{j K} \ln K_{i t}\right)
$$

where $\widehat{\epsilon}_{j}$. denotes the estimated elasticities of value added with respect to the inputs in 4-digit SIC industry $j$.

\footnotetext{
${ }^{9}$ To try to see how much capacity utilization affects measured productivity, we also estimated production functions with the number of production workers (instead of total production worker hours) as our measure of production worker labor. Somewhat surprisingly, this had little affect on our main results. See Appendix E for details.

${ }^{10}$ At the time of this writing we are waiting for IRS approval to access the plant-level Survey of Plant Capacity Utilization (PCU) data. For a subset of our sample, this data will allow use to adjust our plant-level capital services measures for plant-level differences in capital utilization. In future work we also plan to adapt the industry-level proxy methods of Basu (1996) and Burnside, Eichenbaum and Rebelo (1995) for estimating capital utilization at the plant-level.

${ }^{11}$ We compare results across several different production function estimators, including Ordinary Least Squares, Levinsohn and Petrin (2003, LP), and Wooldridge (2005) variant of the LP estimator. The different estimators have different strengths and weaknesses, our preferred estimator is the latter, which corrects for the simultaneous determination of inputs and technical efficiency, is robust to the Ackerberg, Caves, and Frazer (2008) criticism, and is one line of code in Stata, available from the authors on request.
} 
We now turn to the specifics of the data.

\section{The Annual Survey of Manufacturers and Cen- sus Data}

We use the U.S. Census Bureau's Annual Survey of Manufactures and Census of Manufactures, which provide a nationally representative sample for the entire U.S. manufacturing sector. These data include measures of the total (nominal) value of shipments, total expenditures on intermediate and primary inputs, and other input and output measures needed for our estimation.

The Census takes place in the years ending in 2 and 7 , and includes approximately 200,000 manufacturing establishments that make up virtually all of aggregate value added. ${ }^{12}$ The Annual Survey of Manufacturers (ASM) samples between 50,000 and 70,000 plants in U.S. manufacturing. With probability one the ASM samples all plants with more than 250 employees, all plants that are part of very large companies, and all plants in certain industries that are considered important to track. These plants account for approximately half of the sample. The other half includes plants that are sampled from the population with a probability related to the plant's value of shipments within each 5 -digit product class. ${ }^{13}$ The ASM sampling weight applied to these plants is then inversely proportional to the probability that the plant is sampled.

\footnotetext{
${ }^{12}$ There are many other small plants from which data are not collected because they generate very little value added.

${ }^{13}$ The sampling probabilities for other plants are chosen to minimize the total cost of sampling, subject to a set of target variances. The targets are the sampling variances of the estimated change since the last Census in the value of shipments for each 4-digit SIC industry and each 5-digit product class. In 1994, Census changed the algorithm they used to select the sample, but the description above of the sampling weights still remains applicable. In a 1999 Census also increased the threshold for certainty plants to 500 employees. Also, in 1997 Census moved to the NAICS system (although the SIC was also used in 1997), so they changed the industries and product classes for which they are minimizing sampling variances.
} 
While the data we have is from the manufacturing sector and not the entire economy, P-L show that for any subset of plants in the economy we can decompose their contribution to aggregate value added.

While we do observe the plants that are the largest contributors to value added in every year, we do not observe the entire manufacturing sector in every year. In order to account for this, we use the ASM sample weights, which add no error to either PL-APG or its decomposition for the plants sampled with probability one. ${ }^{14}$

Given the definition of plant-level value added (see equation 20) and the ASM sampling weights $w_{i t}$, we estimate aggregate value added in manufacturing as

$$
V A_{t}^{D D}=\sum_{i} w_{i t} V A_{i t}^{D D}
$$

Table 1 shows the annual growth rates of real GDP and four different measures of the growth rates of aggregate real value-added in manufacturing: from the National Income and Product Accounts (NIPA), from the NBERCES manufacturing productivity database, and two different measures from the plant-level ASM data. ${ }^{15}$ To calculate the estimates in column (4), we first used equation (25) to computed aggregate real value-added using all plants in the ASM for which we could compute real value-added, and then we computed the growth rates of these aggregates. For column (5), we selected only plants which are continuers from one year to the next and for which we could compute plant-level estimates of productivity. Then we computed the growth rate of aggregate real value-added as a Tornqvist index, as in the first term in equation (26).

The average annual growth rate (AAGR) of real GDP over this period was about $2.5 \%$, while our estimates of the AAGR of manufacturing value-

\footnotetext{
${ }^{14}$ For those plants that are sampled with probability less than one, the ASM weight need not be representative of the input expenditures and changes in input levels. However, the results presented below in Table 1 indicate that the growth rates of aggregate value-added calculated from the ASM are highly correlated with the estimates of the growth rates of aggregate valued-added from other sources.

${ }^{15}$ Unfortunately real value-added for manufacturing is only available on the BEA website starting in 1987.
} 
added range from $2.3 \%$ for the Tornqvist index based on continuing ASM plants to $3.6 \%$ in the NBER-CES database. The growth rate of manufacturing valued-added was more volatile than that of GDP: our estimates of its standard deviation range from $4.6 \%$ for the Tornqvist index of continuing ASM plants to $6.0 \%$ for the ASM measure that uses all plants. This is compared to a standard deviation of only $2.4 \%$ for the growth rate of real GDP. The correlation between the growth rate of manufacturing valued-added for continuers and the GDP growth rate during this period is 0.78 .

The numbers from the plant-level ASM do not exactly match the aggregate real value-added growth rates from the NIPA both because the samples are different, and because the value-added measures used by the Census Bureau and the BEA are somewhat different. However, the numbers are quite similar in most years.

The differences between columns (4) and (5) illustrate the importance of entry and exit in the ASM. If we exclude the first year of each ASM panelyears ending in 4 or 9 -then in most years the growth rate of aggregate real value-added based on all ASM plants is close to the growth rate computed only for continuing ASM plants. ${ }^{16}$ The biggest departures from this rule occur in 1992 and in 1994-1996. In 1992, it seems that "false" entry (plants that showed up for the first time in the ASM data but previously existed in the LBD) contributed a lot to real valued-added in manufacturing. For 1994-1996, the difference between the Tornqvist index in column (5) and the results in column (4) seems to be related to price indexes in computer-related industries. $^{17}$

Despite the differences in the samples and value-added measures, our estimates from the ASM do generally track the growth rates of manufacturing value-added from other sources. In particular we can clearly see the contractions in 1980, 1982, and 1990/1991, and the expansions in the 1980s and 1990s, and the standard deviation of our estimates of the growth rate of ag-

\footnotetext{
${ }^{16}$ At the beginning of each ASM panel, a little less than half of the plants exit the panel and are replaced.

${ }^{17}$ We discuss entry and exit and the issues related to price indexes in greater detail in Appendix C.
} 
gregate value added (column 5) is about the same as the standard deviation of the growth rates of aggregate value from the NBER-CES productivity database (4.7 versus 4.6 percentage points, respectively). The correlation between our measure of aggregate value-added from continuing ASM plants and manufacturing aggregate real value-added from the NIPA (for the years for which we have real value-added from the NIPA) is 0.97 .

Our estimate of PL-APG from $t-1$ to $t$ is given by

$$
\widehat{P L}_{G, t}=\sum_{i} \bar{D}_{i t}^{v} \Delta \ln V A_{i t}^{D D}-\sum_{i} \sum_{k} \bar{s}_{i k t} \Delta \ln X_{i k t}
$$

where we redefine $D_{i t}$ and $s_{i k t}$ in terms of the ASM sampling weights, with

$$
\begin{gathered}
D_{i t}^{v}=\frac{w_{i t} V A_{i t}^{D D}}{V A_{t}^{D D}}, \\
\bar{D}_{i t}^{v}=\frac{D_{i t}^{v}+D_{i, t-1}^{v}}{2} \\
s_{i k t}=\frac{w_{i t} W_{i k t} X_{i k t}}{V A_{t}^{D D}}
\end{gathered}
$$

and

$$
\bar{s}_{i k t}=\frac{s_{i k t}+s_{i k, t-1}}{2} .
$$

$k$ indexes three primary inputs: production worker labor $\left(L^{P}\right)$, non-production worker labor $\left(L^{N P}\right)$, and capital $(\mathrm{K})$.

We observe the total wage bill both for production workers and nonproduction workers separately and can thus compute $s_{i k t}$ for them directly. For capital expenditures we multiply the plant-level real stock of capital by the 2-digit industry level nominal rental price of capital, denoted $P_{t}^{K}$, and then weight:

$$
s_{i K t}=\frac{w_{i t} P_{t}^{K} K_{i t}}{V A_{t}^{D D}} .
$$

For production workers $\Delta \ln L_{t}^{P}$ is the change in total hours from period $t-1$ to $t$. For non-production workers, $\Delta \ln L_{t}^{N P}$ is the change in the number of laborers from period $t-1$ to $t$. For the change in capital $\Delta \ln K_{t}$ we use the change in the real value of the total capital stock at the plant, constructed using the perpetual inventory method. 
The decomposition is straightforward to calculate given the production function estimates. In the gross output case, the estimate for the change in aggregate technical efficiency is

$$
\sum_{i} \bar{D}_{i t} \Delta \ln \widehat{\omega}_{i t}
$$

where

$$
D_{i t}=\frac{\sum_{i} w_{i t} P_{i t} Q_{i t}}{V A_{t}^{D D}}
$$

As noted in PL, a lower bound on aggregate reallocation is given by

$$
\widehat{P L}_{G, t}-\sum_{i} \bar{D}_{i t} \Delta \ln \widehat{\omega}_{i t}
$$

For any specific input $X_{i j t}$ - either primary or intermediate - the reallocation term is

$$
\sum_{i}\left(\bar{D}_{i t} \widehat{\epsilon}_{j}-\bar{s}_{i j t}\right) \Delta \ln X_{i j t}
$$

The decomposition for reallocation for value added follows the same approach.The change in aggregate technical efficiency is given by

$$
\sum_{i} \bar{D}_{i t}^{v} \Delta \ln \widehat{\omega}_{i t}^{i t}
$$

and for any primary input $X_{i j t}$ the reallocation term is given by

$$
\sum_{i}\left(\bar{D}_{i t}^{v} \widehat{\epsilon}_{j \cdot}-\bar{s}_{i j t}\right) \Delta \ln X_{i j t} .
$$

The Domar weight adjusts because the value-added production function coefficients are different from the gross output coefficients unless there are no intermediate inputs used in production.

We close by discussing our treatment of entry and exit. Entrants and exiters pose no conceptual challenges for the theory, and in the discrete time setting they can be directly included in PL-APG. Decomposing changes in aggregate productivity with entry and exit is straightforward. Decomposing growth rates with entry and exit is a bit trickier, but we can also address this in the PL-APG framework. Note that here we are referring to the oneperiod contribution of entrants and exiters. As noted above, we have an 
unbalanced panel, so we are already including the contribution of entrants after their first year and exiters in all but their last year. We can also measure the cumulative contribution of, for example, plants that entered in 1980. In future work we plan to present more complete empirical results for entrants and exiters. ${ }^{18}$

\section{Estimates of PL-APG using the ASM}

In this section we present estimates of PL-APG from the ASM data and compare these results to estimates of aggregate productivity growth using other indexes and other more aggregate data.

\subsection{PL-APG and Its Decomposition Using Gross Output Production Functions}

Table 2 shows estimated PL-APG and its decomposition (using (26)) for the entire U.S. manufacturing sector. This includes changes in aggregate value-added and changes in the aggregate costs of capital, production-worker labor, and non-production-worker labor. While aggregate value-added in manufacturing grew by an average of $2.3 \%$ per year, aggregate costs of capital and non-production labor grew very little over this period. ${ }^{19}$ The growth rate of aggregate value-added was also much more volatile than the growth rates of aggregate primary input costs.

The final column of table 2 shows our estimates of aggregate productivity growth, PL-APG. Since the growth rates of aggregate primary input costs are close to zero in most years, PL-APG basically follows the growth rate of aggregate value-added. The mean is approximately the same $(2.2 \%$ for PLAPG) and the contemporaneous correlation between aggregate value-added growth and PL-APG is 0.98 .

\footnotetext{
${ }^{18}$ See Appendix $\mathrm{C}$ for empirical results for the effect of entry and exit on measures of the growth rates of aggregate value added in manufacturing.

${ }^{19}$ The biggest outlier is 1982 , when our measure of aggregate production labor costs declined by $3.6 \%$.
} 
Next we decompose PL-APG into productivity growth due to withinplant technical efficiency growth and growth due to the reallocation and fixed cost terms. Column 3 of Table 3 shows the contribution of technical efficiency growth to PL-APG, where plant-level technical efficiency is estimated from the gross-output specification in equation (23). We estimate the production functions by LP, OLS, and the Wooldridge (2005) modification of LP, respectively. Table 3 shows the results from the Wooldridge estimator. ${ }^{20}$ For comparison, Table 3 also includes the growth rates of aggregate real value-added from the ASM (the Tornqvist index from column 5 of Table 1). Total reallocation (column 4) is the sum of the reallocation "gap" terms for primary and intermediate inputs in equation 16 . The contribution of total reallocation is positive in all but 3 years. Intuitively this makes sense. In any reasonably well-functioning market economy one expects inputs to be reallocated over time to activities that on average consumers value more highly. Both technical efficiency and reallocation make important contributions to aggregate productivity growth, both in terms of the average growth rate and the volatility of aggregate productivity growth. Reallocation makes a larger contribution on average, whereas most of the volatility in aggregate productivity growth is coming from aggregate technical efficiency growth. As noted above, our plant-level technical efficiency estimates include measurement error due to differences between the growth rates of plant-specific output prices and the growth rates of industry-level price indexes. In future work we plan to use BLS transaction prices to try to determine how much of the volatility in measured technical efficiency is due to volatility in these prices.

The final column of Table 3 shows the the difference between PL-APG and the sum of the technical efficiency and total reallocation terms. This residual term includes any fixed costs which are not already captured by the technical efficiency term as well as any discrete-time approximation error. ${ }^{21}$

\footnotetext{
${ }^{20}$ Results for the LP and OLS estimators are presented in tables A3a and A3b in the appendix.

${ }^{21}$ It turns out that in most years almost all of this term is explained by approximation error. See Appendix D for details.
} 
In almost all years, the fixed costs residual term is small relative to the total reallocation term in column (1), indicating that the reallocation "gap" terms explain most of the growth of aggregate productivity that is not due to technical efficiency growth.

In Table 4 we present our decompositions of aggregate productivity growth due to reallocation into the contributions of the "gap" terms associated with each factor of production. ${ }^{22}$ The largest share of the annual variation in aggregate productivity growth due to reallocation is coming from variation in the intermediate materials gap term, although production worker labor reallocation is important in some years. Capital's contribution is relatively stable and almost always positive. ${ }^{23}$ The growth rates of the individual gap terms are also less volatile than the aggregate technical efficiency terms in Tables 3.

We are currently investigating the sources of the variation in these gap terms. A particular input for a plant can contribute positively to the reallocation term because of a positive gap and a positive growth rate of that input or because of a negative gap and a decline in the use of that input. Similarly, the importance of reallocation can change over time if the gaps are changing over time or if the gaps are non-zero but constant over time, and only the growth rates of inputs are changing. A priori we think that fixed costs and adjustment costs are less important in the reallocation of intermediate materials than for reallocation of labor and capital. However, imperfect competition can also drive a wedge between the marginal product and the marginal cost of intermediate materials. We suspect that the large fluctuations in the contribution of reallocation of intermediate materi-

\footnotetext{
${ }^{22}$ Table 4 presents the results for the Wooldridge production function estimator. The results for the LP and OLS estimators are presented in table A4a and A4b in the appendix.

${ }^{23}$ Recall that for the LP estimator (Appendix Table A4a) we used energy as a proxy variable and did not estimate the output elasticities for energy. We did this because this specification gave us more reasonable (i.e., non-negative) production function parameter estimates for most industries. Ex ante this seemed harmless, since energy has a relatively small cost share in most industries. However, the results in Table 4 and Appendix Table A4b for the Wooldridge and OLS estimators show that despite its relatively small cost share, reallocation of energy makes a significant contribution to aggregate productivity growth in some years.
} 
als is due to large fluctuations in the growth rates of intermediate materials and relatively constant gaps between the output elasticities and input cost shares.

\subsection{Value-added Results}

The results in Tables 3 and 4 are constructed from gross-output production functions. For macroeconomic analysis, value-added production functions are more convenient, but they require stronger conditions on the production technology (e.g. separability of intermediate inputs). For the U.S. Manufacturing data, value-added production functions have another advantage. For the gross-output specifications, we need energy deflators, because we used the real cost of energy when we estimated the production fuctions. We do not have energy deflators for the SIC industry coding system after 1996. For value-added production functions this does not pose a problem, and thus we can use more years of data. Furthermore, for the gross-output specification many plant-year observations are dropped from the sample because some of the energy data is zero or missing. Thus for the value-added specification we can use a larger sample of plants. How much do the value-added specification and the different sample change our results?

While aggregate value-added and PL-APG are invariant to the specification of the production function, we want to use the same samples for aggregate value-added and PL-APG that we use for the decompositions. Therefore we re-estimate aggregate final demand and each of the components of PL-APG for the value-added production functions sample for 19771999. The results are presented in tables A1 and A2 in the appendix. Not surprisingly, these results are similar to the results presented in Tables 1 and 2 .

Columns 3 and 4 of Table 5 present the results of the decomposition of PL-APG into aggregate technical efficiency and total reallocation, where the value-added production functions are estimated by the Wooldridge (2005) modification of the LP estimator. ${ }^{24}$ Comparing these results to the gross-

\footnotetext{
${ }^{24}$ Unlike the gross-output productivity decompositions, in our value-added productivity decompositions, the reallocation terms and the technical efficiency term sum to aggregate
} 
output results in Table 3, the most striking difference is that for the valueadded specification the total reallocation term (column 4 ) is even more stable: its standard deviation is only 0.5 (compared to 1.7 in the gross-output specification), and it is (slightly) negative in only 1 year-1982. As in the gross-output case, the total reallocation term makes a significant contribution to aggregate productivity growth-about 1 percentage point per year. In the value-added specification, aggregate technical efficiency (column 3) is much more volatile than reallocation-the standard deviation is 2.6-and it also contributes about 1.6 percentage points per year to PL-APG over the period 1976-1999.

As shown in equation (19), if the elasticity of output with respect to intermediates is not equal to the ratio of the expenditure on intermediates to total revenues, then the residuals from the value-added production function includes a term related to this gap. As we saw in column 4 of table 4 , these intermediate "gap" terms are important in several years. This may explain why the aggregate technical efficiency term from the value-added production function specification (column 3 of Table 5) is so much more volatile than the total reallocation term (column 4 of Table 5)-some of the volatility in the valued-added "technical efficiency" is actually due to reallocation of intermediates. Tables A5a and A5b show that these results are robust to estimating the value-added production functions by OLS and the LP estimator: aggregate technical efficiency is more volatile than aggregate reallocation, and aggregate reallocation usually contributes positively to aggregate productivity growth.

Table 6 presents the results of the reallocation decomposition in equation (12). The main difference from the gross output results in Table 4 is that there are no reallocation terms for intermediate inputs in Table 6 . In light of equation (19), and the results for the intermediates materials gap term in Table 4, we may want to interpret the results in Tables 5 and 6 with some caution.

productivity growth. In other words, there is no fixed costs residual/approximation error residual. The approximation error discussed in Appendix D does not arise when we use value-added production functions. 


\subsection{Comparing PL-APG to Productivity Measures Based on More Aggregate Data}

We are the first to estimate PL-APG using plant-level U.S. manufacturing data. However, Basu and Fernald (2002) have estimated aggregate produc-

tivity growth and a similar decomposition using annual industry-level data for the entire U.S. private business economy. Over the period most comparable to ours (1974-1989), they compute an average annual productivity growth rate of 0.32 and a standard deviation of 2.22 . The mean and standard deviation of our aggregate productivity growth over the period 1976 to 1996 are $2.2 \%$ and $3.7 \%$. Their estimates of the average annual growth rate of technical efficiency range from $0.14 \%$ to $0.22 \%$, and the standard deviations of their technical efficiency growth rate range from $1.49 \%$ to $1.60 \%$. Our estimates of the mean of aggregate technical efficiency growth range from $0.2 \%$ to $0.6 \%$ and our estimates of the standard deviation range from $2.6 \%$ to $3.0 \%$.

Our total reallocation term is generally positive, averaging $1.7 \%$ to $2.1 \%$ growth per year in the gross output specification. This result-a generally positive reallocation term-makes sense: in a market economy populated by profit-maximizing firms, on average, in the long run, one expects resources to be reallocated from uses with lower marginal products to uses with higher marginal products. However, this result contrasts with Basu and Fernald's (2002) results using a similar decomposition. Over the period 1959 to 1989, their estimates of the average annual growth rate due to reallocation range from -0.082 percent to -0.16 percent. As noted above, Basu and Fernald's results are not directly comparable to ours, because they study a different time period, and they use data covering the entire private business economy, whereas we study only manufacturing. However, our results are much less likely to suffer from aggregation bias as we are working at the plant level. Furthermore, in a well-functioning market economy populated by profitmaximizing firms, it is difficult to understand why aggregate reallocation would contribute negatively to aggregate productivity growth on average 
over a period of many years. ${ }^{25}$ Despite these differences, like us, Basu and Fernald find that the reallocation term is less volatile than the technical efficiency term (which they call the "corrected technology residual"). Their estimates of the standard deviation of their reallocation term range from 0.99 to 1.11 , whereas the standard deviation of their technical efficiency term is about 1.65 .

\subsection{Comparing PL-APG to Productivity Measures Based Only on Technical Efficiency Change}

While we are the first to apply the PL-APG decomposition to U.S. data, many studies have used the ASM and CMF to decompose aggregate productivity growth using some variant of the BHC productivity index, like those found in Foster, Haltiwanger, and Krizan (2001) and Olley and Pakes (1996). These indices are defined completely in terms of the plant-level technical efficiency residual. In continuous time the BHC index is given as:

$$
B H C \equiv d \sum_{i}\left(s_{i} \ln \omega_{i}\right)=\sum_{i} s_{i} d \ln \omega_{i}+\sum_{i} \ln \omega_{i} d s_{i},
$$

where $s_{i}$ is either the gross-output share or the labor share for plant $i$. The $\mathrm{BHC}$ measure decomposes into the two right-hand-side terms. The first term is referred to as the technical efficiency or "within" term and the second term is known as the reallocation or "between" term.

$\mathrm{BHC}$ growth measured with discrete time data and the Tornquist-Divisia approximation is then

$$
B H C_{t}=\sum_{i} s_{i t} \ln \omega_{i t}-\sum_{i} s_{i, t-1} \ln \omega_{i, t-1}
$$

\footnotetext{
${ }^{25}$ The fact that Basu and Fernald's data covers the entire economy makes their generally negative reallocation result even more surprising. When an industry or sector is in decline, resources are reallocated away from that industry. If one measures reallocation only for that industry, then it may be negative because resources are being reallocated from uses with positive marginal products to uses with zero marginal product (because the uses are outside that particular industry and therefore not measured). But it is difficult to make this argument for the entire U.S. economy over the period 1959 to 1989-aggregate labor, capital, and intermediate inputs were all growing in the U.S. over this period.
} 
with decomposition

$$
B H C_{t}=\sum_{i} \frac{\left(s_{i t}+s_{i, t-1}\right)}{2} \Delta \ln \omega_{i t}+\sum_{i} \frac{\left(\ln \omega_{i t}+\ln \omega_{i, t-1}\right)}{2} * \Delta s_{i t} .
$$

On the technical efficiency term, the BHC-type indexes use either labor share or gross output share as the weight, where PL-APG weights by the Domar weight. The only case in which the Domar weight will equal the gross output share is when there are no intermediate input deliveries in the economy. Otherwise the difference between the two is increasing in the fraction of gross output that goes to intermediate input use. For example, if every plant has a ratio of materials expenditures to revenues of $50 \%$ (typical for manufacturing), then the BHC technical efficiency growth is exactly half of PL-APG technical efficiency growth.

Empirically we want to focus on the differences in reallocation between BHC and PL-APG, so we abstract from differences in technical efficiency by using the Domar weight for both BHC and PL-APG technical efficiency growth. To compare the BHC index to PL-APG, we computed BHC and the $\mathrm{BHC}$ reallocation term using the same set of plants that we used for PLAPG and its decompositions. The results are presented in columns 5 and 6 of Tables A10a-c. The Domar-weighted BHC index is much more volatile than PL-APG. Since we abstract from differences in the weights used to aggregate technical efficiency, the BHC technical efficiency term is the same as the technical efficiency term in the PL-APG decomposition. Therefore all of the excess volatility in the $\mathrm{BHC}$ index relative to PL-APG is because of the reallocation term. The BHC reallocation term also frequently takes negative values, in some cases large negative values. In a market economy populated by profit-maximizing firms, it is difficult to see why reallocation of primary inputs should have such large negative effects on aggregate productivity growth. This finding of excess volatility and large negative values in the $\mathrm{BHC}$ reallocation term is robust to different production function estimators and different economies (see Petrin and Levinsohn, 2008 and Kwon, Narita, and Narita (2009)). 


\section{Implications for Models of Business Cycle Fluc- tuations}

What are the implications of these results for models of business cycle fluctuations? We distinguish between two sources of aggregate productivity growth: growth of plants' output for a given level of inputs-technical efficiency growth-versus reallocation across plants (and industries). We find that most of the aggregate volatility can be directly attributed to the former. However, in all of our gross-output specifications we find that reallocation makes a significant contribution to aggregate volatility, with a standard deviation ranging from 1.1 to 1.7 percentage points, depending on the estimator. Under perfect competition with no adjustment costs or distortions, in equilibrium reallocation makes no contribution to aggregate productivity growth, because marginal revenue products are always set equal to marginal costs. Thus our findings suggest that imperfect competition, frictions or distortions of some sort play an important role in aggregate fluctuations at business cycle frequencies.

As emphasized by Rotemberg and Woodford (1995) and Basu and Fernald (2003), under imperfect competition, reallocation can serve to propagate technology shocks. What begins as a pure technology shock may have lagged effects on aggregate productivity through the reallocation of resources across plants and industries. But aggregate demand shocks such as changes in government purchases may also affect aggregate productivity through the reallocation channel. Therefore our results do not force us to take a stand on the ultimate sources of business cycle fluctuations. We do take a stand on appropriate models of business cycle fluctuations. As shown in equation 19, if the elasticity of output with respect to an intermediate input is not equal to the ratio of expenditure on the input to total revenues, then residuals from value-added production functions are not pure technology shocks. ${ }^{26}$ In addition to the technology shock, the value-added residuals

\footnotetext{
${ }^{26}$ Rotemberg and Woodford (1995) and Basu and Fernald (2003) and emphasize the same problem with using value-added production functions to measure productivity in the presence of imperfect competition.
} 
include a "gap" term for the effect of intermediate inputs. Our results in Tables 4 and A4a-b indicate that the intermediate input "gap" terms are quite important. Comparing the gross-output results in Tables 3 and A3a-b to the value-added results in Tables 5 and A5a-b, the value-added specification seems to attribute too much of the volatility in aggregate productivity growth to technical efficiency growth, and too little to reallocation. Our results indicate that business cycle models that assume the existence of a valued-added production function in an economy with perfect competition and no frictions or distortions attribute too much to the direct effect of technology shocks and miss an important channel for the propagation of business cycles.

\section{Conclusions and Suggestions for Further Research}

We provide the first application of the Petrin and Levinsohn (2008) aggregate productivity growth statistic and decomposition to U.S. data. We adopt this definition because it insists that micro-level changes add up to changes in aggregate final demand holding primary inputs constant. We decompose aggregate productivity growth into the contributions of technical efficiency and reallocation. Over the period 1976-1996, in the U.S. manufacturing sector we find that both contributions are important. On average reallocation was responsible for about 1.7 to 2.1 percentage points per year, and it was positive in all but 3 years. Technical efficiency growth was responsible for only 0.2 to 0.6 percentage points per year, but it was more volatile: our estimates of the standard deviation of the annual growth rate range from 2.6 to 3.0 percentage points, compared to 1.1 to 1.7 percentage points for reallocation. While these results are robust to several different production function estimators, they are not robust to using the popular BHC index on annual data. We argue that this is because the BHC index does not accurately measure aggregate productivity growth in an economy with distortions and imperfection competition.

We have found that reallocation has been an important factor in aggregate productivity growth and aggregate fluctuations in U.S. manufacturing. 
We suspect that reallocation is even more important in other economies, especially economies transitioning from communism to capitalism or economies with less factor mobility or more distortions than the U.S. economy. In these economies, we expect to find larger gaps between marginal revenue products and marginal costs, and thus reallocations should have larger effects on aggregate productivity growth. Based on economic theory and the empirical evidence presented here, we argue that the PL-APG measure would provide a better measure of aggregate productivity growth and the contribution of reallocation to aggregate productivity in these economies. 


\section{Appendix A: Data}

We use the Census Bureau's confidential Census of Manufactures (CMF, conducted in years ending in 2 and 7), the Annual Survey of Manufactures (ASM), and the Bureau's Longitudinal Business Database (LBD). In Census years we use only the plants receiving the ASM questionnaire, since that survey instrument askes more detailed questions about costs than the non-ASM questionnaire sent to other plants in the Census years. The LBD is described in Jarmin and Miranda (2002). For deflators and depreciation rates we use the dataset available on John Haltiwanger's web site: http://www.econ.umd.edu/ haltiwan/capital/CRIWNBER/external.sas7bdat (last accessed on October 1, 2008).

Our unit of analysis is the plant. This is consistent with the way inputs and outputs are measured in the surveys-respondents are asked to treat each plant as a separate economic unit. Consistent with most researchers who use this microdata, we drop administrative records plants from the sample, because most of the cost data for these plants is imputed.

Industry coding. We use SIC industry codes at the 4-digit level. The SIC system of coding industries has changed over time, most notably in 1987 and in 1997. Since we are estimating production functions by industry, we need to have consistent industries over time (or greatly reduce our sample size for some industries). The Census Bureau makes its greatest effort at accurate plant level industry coding in the census years. There was a major revision of the SIC coding system in 1987. However, in the CMF years, the plants have been recoded using the 1987 SIC system based on the 7-digit products that the plants were producing in each CMF year. Thus we use the 1987 SIC coding system and the Census years to create consistent 4-digit SIC industries across time using the microdata. In cases where we could not recode industries this way, we use a concordance from the 1977/1982 SIC system to recode the plants into the 1987 SIC system. Our coding scheme gives us 459 industries.

Production-worker hours. Thousands of total annual plant hours worked 
by production workers at a plant are measured directly in the ASM and CMF. For production worker costs in the numerator of equation (8), we use total annual production worker wages at the plant. The ASM only collects total non-wage costs of labor for an entire plant-it does not disaggregate non-wage labor costs into non-wage costs for production and non-production workers. Furthermore, non-wage labor costs in the ASM have a high item non-response rate and thus many plants have imputed data for this item (see Dunne and Roberts (1993)). Non-production-worker hours are not measured directly in the surveys. We construct a measure of thousands of total non-production-worker hours by subtracting the number of production workers at the plant from the total number of employees at the plant and then multiplying the difference by 50 weeks times 40 hours per week and dividing by 1,000. For non-production worker costs we use total salaries and wages less total production worker wages at the plant.

Value-added. Nominal value-added is nominal total value of output minus the nominal value of intermediate inputs (VM). Our measure of doubledeflated real value-added is the real total output minus the real total cost of intermediates. See below for our measures of output and intermediate inputs.

Output. The nominal dollar total value of shipments, TVS, is observed in the ASM/CMF. Note that the surveys ask multi-plant firms to report the operations of each plant as a separate economic unit. Thus the shipments from one plant to another plant in the same firm are supposed to be included in the total value of shipments of the shipping plant, and they are supposed to be included in the total cost of materials of the receiving plant. We also observe inventories for finished goods and work-in-progress at the beginning and end of the year (FIB, FIE, WIB, and WIE). Our measure of real gross output is $($ TVS $+($ FIE-FIB $)+($ WIE-WIB $) /$ PISHIP, where PISHIP is the 4-digit SIC industry-level shipments deflator from the NBER/CES Productivity database.

Intermediate inputs. The total cost of intermediate inputs (VM) is the sum of the cost of materials and parts $(\mathrm{CP})$, the cost of fuels $(\mathrm{CF})$, the 
cost of purchased electricity (EE), the cost of resales (CR), and the cost of contract work (CW), all measured in nominal dollars. The real total cost of intermediates is VM/PIMAT, where PIMAT is the 4-digit industrylevel deflator for materials from NBER-CES productivity database. For the gross-output production functions, we also break out intermediate inputs into the real cost of materials, $(\mathrm{CP}+\mathrm{CR}+\mathrm{CW}) / \mathrm{PIMAT}$, and the real cost of energy, $(\mathrm{CF}+\mathrm{EE}) / \mathrm{PIEN}$, where PIEN is the energy deflator from the NBER-CES productivity database.

Capital. We use the perpetual inventory method to construct a measure of total real capital stock for each plant using the book value of the plant's assets (appropriately deflated), the plant's real capital expenditures (including rentals of equipment and structures), and industry-specific capital depreciation rates. For each plant we construct separate stocks for machinery/equipment and building/structures, and then we sum them to get the total capital stock for the plant.

The initial capital stock is the book value of assets at the beginning of the year deflated to thousands of 1987 dollars using industry-level asset deflators. For example, for equipment, the real initial capital stock is computed as: initial stock $=($ initial nominal book value $) *($ nkceq/gkheq $) *($ piinve87/piinve96 $)$, where $n k c e q=$ the real value of net equipment capital stock in millions of 1996 dollars for a given year for an entire 2-digit SIC industry; gkheq = the book value of gross equipment capital stocks (in millions of historical dollars) for a given year for an entire 2-digit SIC industry; piinve96 = the 3-digit industry equipment investment deflator (PIINVE) for 1996, where 1987 is the base year; piinve $87=1$. We follow an analogous procedure for buildings or structures. After the initial year, the plant's capital stock is the undepreciated stock from the previous year plus total real capital expenditures from the previous year. To construct the capital cost shares in equation (8), we need an estimate of the user cost of capital. We use equipment ("machinery") capital rental prices (at the 2-digit SIC industry level) and the structures ("buildings") capital rental prices constructed from BLS data.

In later years we have to deal with several missing data issues to construct 
our capital stocks measures. In 1986 the ASM stopped collecting the book value of assets in non-census years. For plants that enter the ASM after 1986 and survive until a census year, we construct initial capital stocks using backwards and forwards perpetual inventory, starting in the first census year that the plant is observed. Furthermore, after 1992, the ASM only collected the total book value of assets, rather than separate book values for machinery and buildings. To impute the book value machinery assets in 1997, we accumulate the plant's expenditures on machinery over all the years of the plant's existence prior to 1997 and multiply the total assets variable by the ratio of cumulated machinery investment to total investment over the same period. We follow the analogous procedure for investment in buildings. 


\section{Appendix B: BHC Discussion}

Several previous studies have used the U.S. plant-level manufacturing data to compute variants of the BHC index and the technical efficiency growth. How do our results for the BHC index compare? Lee (2005) uses the Annual Surveys of Manufactures to study the entire manufacturing sector. Using the Bailey, Bartelsman, and Haltiwanger (1996) variant of the BHC index, Lee finds that reallocation is at least as volatile as technical efficiency growth. In contrast, using only the quinquennial censuses and 23 manufacturing industries, Baily, Hulten, and Campbell find that on average the reallocation term (which they call the "share effect") is much less volatile than the technical efficiency term. Furthermore, for given 5-year periods and single industries, $\mathrm{BHC}$ find that their reallocation term is always positive, and almost always smaller in absolute value than their technical efficiency growth term. Similarly, Foster, Haltiwanger, and Krizan (2001, table 7, panel B) report that among continuing plants, technical efficiency growth (the "within share") explains a much higher percentage of the overall growth in total factor productivity than reallocation (the "between share").

What explains the discrepancy between our BHC results in table 3 and Lee (2005) on the one hand, and, on the other hand, the results of BHC and Foster, Haltiwanger, and Krizan? One obvious difference is that we (and Lee) use annual data, whereas the other studies use quinquennial data. As mentioned above, at higher frequencies, factor utilization probably has more of an effect on measured total factor productivity. Our measure of production worker labor is hours. So for this input, we do measure utilization, however imperfectly. Utilization of non-production workers and capital is not measured in the ASM/CMF data. Therefore, some of the variation in our measure of technical efficiency is probably variation in factor utilization. For example, suppose that plant-level technical efficiency does not change from year $t$ to $t+1$, but because of a negative demand shock, the plant manager runs fewer shifts per week, or runs the machinery at a slower rate. Since we do not directly measure utilization of capital, the BHC index would show an increase in within-plant technical efficiency growth even though there was none. Since factor utilization and (measured) aggregate 
productivity are both procyclical, mismeasurement of capital utilization may explain why the BHC index is not highly correlated with aggregate final demand growth in our annual data (see table 3). Note, however, that the PL-APG measure in equation (26) suffers from the same measurement error in capital services. Thus it is not clear that capital utilization can explain the discrepancies between PL-APG and the BHC measure in annual data.

Another difference between our BHC results and those of previous studies is that most previous studies have used output-share weights or labor-share weights, whereas we use Domar weights to construct our BHC-like index. The consensus in the literature is that Domar weights are the correct weights to use if you want to measure aggregate productivity. However, our use of Domar weights may explain some of the difference between our results for the BHC-like index and previous results in the literature.

Another explanation for the discrepancy between our BHC estimates from annual data and estimates from other studies using quinquennial data is that this is exactly what we should expect. At the 5-year interval, only plants that survive for 5 years are considered continuers. These tend to be bigger plants, which are less likely to experience large growth rates. Thus the weight-change $d D_{i t}^{v}$ in the second term in equation (39) is less likely to be large at the 5-year interval than at the 1-year interval. On the other hand, entry and exit become more important at longer intervals. Indeed, FHK (table 7, panel B) find that at the 5-year interval, net entry's contribution to their BHC-like index is as large or larger than the contribution of reallocation among continuing plants. In contrast, using annual ASM data, Lee (2005) finds that the contribution of net entry is small compared to the contribution of reallocation among continuing plants.

While no economic theory maps the $\mathrm{BHC}$ index or the $\mathrm{BHC}$ reallocation term to aggregate productivity growth, many researchers have interpreted it this way. For example, in their excellent review and synthesis of studies using several variants of the BHC index and its decomposition, Foster, Haltiwanger and Krizan (1998) provide the following summary: "the contribution of reallocation of outputs and inputs from less productive to more productive establishments plays a significant role in accounting for aggregate productiv- 
ity growth." Foster et al. are not alone. Other studies interpreting changes in the BHC index and its variants as measures of aggregate productivity growth include Baily, Hulten, and Campbell (1992, p. 208), Baily, Bartelsman, and Haltiwanger (2001, p. 422), Lee (2005, p. 8), and Brown and Earle $(2008$, p. 1). The point is not to single out these papers. The point is that variants of the $\mathrm{BHC}$ index and its reallocation term have been widely interpreted as measuring aggregate productivity growth. Petrin and Levinsohn (2008) show that this interpretation is problematic from the standpoint of economic theory: the $\mathrm{BHC}$ index can diverge significantly from aggregate productivity growth. With the caveat that both PL-APG and BHC-like indexes are subject to the measurement issues mentioned above, the results in Tables A10a-c show that in annual U.S. manufacturing data, the Domarweighted BHC index does significantly diverge from aggregate productivity growth. 


\section{Appendix C: Entry and Exit}

As mentioned in the main text, although we can compute the contribution of entrants and exiters to aggregate productivity growth, we can only compute the plant-level growth rate decompositions for plants that continue from one year to the next. Plants that enter in year 1 , continue to year 3 and exit in year 4 are included in the productivity growth decompositions years 2 and 3, but excluded in years 1 and 4 . Dealing with entry and exit is further complicated by the fact that about half the ASM-typically smaller plants-is a 5-year rotating panel. For these smaller plants, we want to distinguish between a plant actually starting up or closing down versus panel rotation. To do this, we use the LBD. The LBD does not contain measures of value-added or detailed cost measures, but in principle it covers all employer establishments in every year. We define a plant as a "true" entrant in year $t$ if its first year in the LBD was year $t$ or $t-1$. "False" entrants in year $t$ are thus plants that enter the ASM in year $t$ but were in the LBD in year $t-2$ or earlier. Similarly, "false" exits are plants that exit the ASM in year $t$, but continue in the LBD in year $t+2$ or later. $^{27}$

\footnotetext{
${ }^{27}$ Davis, Haltiwanger, and Schuh (1996, DHS hereafter) describe an alternative method for identifying false entry and exit in the ASM. Using only the ASM data and knowledge of Census Bureau industry coverage codes, they create a set of linkage files that identify each plant-year as a birth, a continuer, or a death. DHS created files for 1972-1988. The linkage files were extended by C.J. Krizan and John Haltiwanger to cover 1989-1993 and Foster, Haltiwanger, and Kim (2006) extended the files to 1994-1998. Unfortunately, because of a change in the way the Census Bureau deals with entrants in the ASM, in 1989 the linkage files include only a fraction of the plants that are in the ASM. In addition, these linkage files were created before Ron Jarmin and Javier Miranda constructed the Longitudinal Business Database. The extended DHS linkage files use the Permanent Plant Number $(\mathrm{PPN})$ as the longitudinal identifier, rather than the LBD's longitudinal identifer, the lbdnum. Jarmin and Miranda (2002) argue that as a longitudinal identifier, the PPN is sometimes problematic. For example, the PPN sometimes changes when ownership status of the plant changes, either because of mergers and acquisitions or because of a change in the legal form of ownership (partnership, corporation, etc.). In these cases, the longitudinal linkage of the PPN will be broken even though the plant continues to produce the same goods in the same location. Jarmin and Miranda use the PPN linkages as the starting point for the lbdnum, but they fix the broken PPN linkages by supplementing it with name and address matching. For these reasons we decided to use the lbdnum rather
} 
In the first column of Table A5, we reproduce our estimates from column (4) of Table 1 . These are the growth rates of aggregate real value-added estimated using every ASM plant with non-missing value-added. Next we select only the plants for which we can construct input costs-call this the estimation sample-and we include only plants that continue from year $t-1$ to year $t$. Then we estimate the aggregate growth rate in the same way that we did in column (1): we aggregate up within each year and compute the growth rates of this aggregate. These estimates are shown in column (2).

The biggest differences between columns (1) and (2) occur at the beginning of the ASM panels-years ending in 4 or 9-and in 1992. The beginning of each ASM panel includes both "true" entry and exit and panel rotation. So it seems likely that excluding entrants and exits in these years causes sample selection bias-although the bias changes signs. To check this hypothesis, we start with the same estimation sample, but then instead of excluding all entry and exit, we only exclude plants that are "true" exits in year $t-1$ or "true" entrants in year $t$. Then we construct the growth rates in the same way as before. Column (3) shows the results.

As expected, now the growth rate at the beginning of each ASM panel is much closer to the growth rate computed using all ASM plants. Surprisingly, in 1992 the growth rate is also much closer, indicating that "false" entrants and exits explain most of the difference between the growth rates from the full sample versus the sample of continuers. Another surprise appears in column (3): in 1980, the growth rate is much lower than the rates in both columns (1) and (2), and in 1981 it is much higher. This appears to be caused by selecting the estimation sample. When we compute aggregate value-added based on the entire estimation sample (i.e., excluding plants with zero or missing values for output or input measures, but including entrants and exiters for which we can compute these measures), then we get the results shown in column (4).

Finally, in column (5) of Table A5 we reproduce the estimates shown in column (5) of Table 1 and column (1) of Table 2. Recall that these estimates than the extended DHS linkage files to distinguish between "true" and "false" entry and exit in the ASM. 
are constructed as in the first term in equation (26): first we compute the first-difference of the log of real value-added for each continuing plant, and then we aggregate using the two-year averages of the plant's value-added share weights. Note that the samples used to construct the estimates in column (5) are exactly the same as the samples used in column (2). Although there are significant differences in other years, the largest differences between columns (2) and (5) occur in 1994-96. These are also the years when the quality-adjusted price indices for the computer-related industries begin to show huge declines and these industries simultaneously contribute a greater share of aggregate value-added in manufacturing. Plants in these industries experienced huge growth rates in real value-added in these years. It seems that the approximation error caused by the log-difference approximation to the plant level growth rates was large enough in these years to cause the growth rate of the Tornqvist index (column 5) to diverge from the growth rates computed as in column (2). 


\section{Appendix D: Approximation Error}

In continuous time, equation (9) shows that PL-APG equals its decomposition into technical efficiency growth, growth due to reallocation, and the growth of fixed costs. The discrete-time approximations to PL-APG and its decomposition both include approximation error which adds an error term to equation (16). Since we do not observe fixed costs, this approximation error is included in the "fixed costs" term. To see the source of this approximation error, note that the discrete-time approximation of PL-APG is given by:

$$
\widehat{P L}_{G, t}=\sum_{i} \bar{D}_{i t}^{v} \Delta \ln V A_{i t}^{D D}-\sum_{i} \sum_{k} \bar{s}_{i k t} \Delta \ln X_{i k t}
$$

where

$$
V A_{i t}^{D D}=\frac{P_{i t} Q_{i t}}{P_{t}}-\frac{P_{i M t} M_{i t}}{P_{t}^{M}}-\frac{P_{i E t} E_{i t}}{P_{t}^{E}}
$$

The discrete-time approximation of the decomposition of PL-APG is:

$$
\begin{aligned}
P L_{G, t}= & \sum_{i} \bar{D}_{i t} \sum_{k}\left(\varepsilon_{i k}-\bar{c}_{i k t}\right) \Delta \ln X_{i k t}+\sum_{i} \bar{D}_{i t} \sum_{j}\left(\varepsilon_{i j}-\bar{c}_{i j t}\right) \Delta \ln M_{i j t} \\
& -\sum_{i} \bar{D}_{i t} \Delta \ln F_{i t}+\sum_{i} \bar{D}_{i t} \Delta \ln \omega_{i t},
\end{aligned}
$$

where we estimate $\ln \omega_{i t}$ by:

$$
\begin{aligned}
\ln \widehat{\omega}_{i t}=\ln \frac{P_{i t} Q_{i t}}{P_{j t}} & -\left(\widehat{\epsilon}_{j P} \ln L_{i t}^{P}+\widehat{\epsilon}_{j N P} \ln L_{i t}^{N P}+\widehat{\epsilon}_{j K} \ln K_{i t}\right. \\
& \left.+\widehat{\epsilon}_{j M} \ln M_{i t}+\widehat{\epsilon}_{j E} \ln E_{i t}\right)
\end{aligned}
$$

The elasticities multiplied by their respective inputs in (44) exactly cancel out their respective terms in the reallocation "gap" terms, leaving us with:

$$
\begin{aligned}
P L_{G, t}= & \sum_{i} \bar{D}_{i t} \Delta \ln \frac{P_{i t} Q_{i t}}{P_{j t}}-\sum_{i} \bar{D}_{i t} \sum_{k} \bar{c}_{i k t} \Delta \ln X_{i k t}-\sum_{i} \bar{D}_{i t} \sum_{j} \bar{c}_{i j t} \Delta \ln M_{i j t} \\
& -\sum_{i} \bar{D}_{i t} \Delta \ln F_{i t},
\end{aligned}
$$

In continuous time, the Domar weight times the revenue share of input $\mathrm{j}$ is equal to the share of input $\mathrm{j}$ 's cost in aggregate value-added: $D_{i t} c_{i k t}=$ 
$s_{i j t}$. In practice, it turns out that the discrete-time approximations of these objects are very close to zero in almost all years. So, in almost all years, the cost-share weighted primary inputs in (43) essentially cancel out the Domarweight times the revenue-share weight times the primary input growth rates in (45). Once we cancel these terms in both equations and rearrange terms, this leaves us with the following approximation:

$$
\begin{aligned}
\sum_{i} \bar{D}_{i t} \Delta l n F_{i t} & \stackrel{=}{\sum_{i}} \bar{D}_{i t} \Delta \ln \frac{P_{i t} Q_{i t}}{P_{j t}} \\
& -\sum_{i} \bar{D}_{i t} \bar{c}_{i M t} \Delta \ln \left(\frac{P_{i M t} M_{i t}}{P_{t}^{M}}\right) \\
& -\sum_{i} \bar{D}_{i t} \bar{c}_{i E t} \Delta \ln \left(\frac{P_{i E t} E_{i t}}{P_{t}^{E}}\right) \\
& -\sum_{i} \bar{D}_{i t}^{v} \Delta \ln \left(\frac{P_{i t} Q_{i t}}{P_{t}}-\frac{P_{i M t} M_{i t}}{P_{t}^{M}}-\frac{P_{i E t} E_{i t}}{P_{t}^{E}}\right)
\end{aligned}
$$

Under our assumptions the continuous-time version of the first three summation terms on the right hand side of equation 46 equal the last summation term. In discrete time, due to approximation error, these two expressions are not necessarily equal. Any differences between the first three terms on the right hand side and the last term on the right hand side will be dumped into our "fixed costs" residual term. Table A6 shows that our "fixed costs" residual term is almost completely explained by this discrete-time approximation error. Column 1 shows the fixed costs residual term from the grossoutput specification, where the production functions are estimated by the Wooldridge-LP estimator. That is, these residuals are constructed by computing PL-APG and subtracting aggregate technical efficiency growth and the sum of the reallocation "gap" terms, just as in column 7 of table 4c. Column 2 of Table A6 shows the discrete-time versions of the right hand side of equation 46. Column 3 shows the difference between columns 1 and 2 . 


\section{Appendix E: Capacity Utilization-the Case of Production Worker Labor}

Previous research (see, for example, Basu (1996) and Burnside, Eichenbaum, and Rebelo (1995)) has found that variation in capacity utilization over the business cycle can affect estimates of aggregate technical efficiency growth. For example, suppose we use the number of production workers at a plant as our measure of production worker labor input. Suppose the number of workers at a plant stays constant while the number of hours per worker increases when demand is high. Then, other things equal, our measure of plant-level level productivity would attribute too much of the increase in output to an increase in productivity. The same measurement error can occur if utilization of the plant's capital stock varies with output. As mentioned in the main text, we do not currently have measures of capital utilization. However, we can address the issue of utilization of production worker labor, since we observe both the number of production workers and the number of production worker hours at the plant.

In all the results in the main text of the paper, we used production worker hours as our measure of production worker labor. To see how much of a difference labor utilization makes, we also constructed estimates of PLAPG using the number of production workers as our measure of production worker labor. Column 1 of Table A7 presents the results. For comparison, column 2 of Table A7 repeats the results from column 5 of Table 2-using production worker hours as the measure of production worker labor. With the exception of one or two years, we find that utilization of production workers has very little effect on our estimates of aggregate productivity growth.

Labor utilization can affect our estimates of aggregate productivity growth through two channels-the effect on our estimates of aggregate technical efficiency growth and the effect on reallocation. To see the effect on aggregate technical efficiency growth, we re-estimated each plant's technical efficiency growth using the number of production workers at the plant as the measure of production worker labor. The results for the Levinsohn-Petrin production function estimator are presented in column 4 of Table A7. For comparison, 
column 5 of Table A7 repeats our results for aggregate technical efficiency growth when we used production worker hours as the measure of production worker labor. For all but three years (1980, 1982, and 1983), using the number of production workers instead of production worker hours has very little effect on our estimates of aggregate technical efficiency growth.

\section{References}

Ackerberg, D., K. Caves, and G. Frazer (2008): "Structural Identification of Production Functions," Working Paper.

Bailey, M. N., E. Bartelsman, and J. Haltiwanger (1996): "Labor Productivity, Structural Change, and Cyclical Dynamics," NBER Working Paper 5503.

Baily, M., C. Hulten, and D. Campbell (1992): "Productivity Dynamics in Manufacturing Plants," Brookings Papers on Economic Activity.

BAsu, S. (1996): "Procyclical Productivity: Increasing Returns or Cyclical Utilization?," The Quarterly Journal of Economics, 111(3), 719-751.

Basu, S., And J. Fernald (1995): "Are Apparent Productive Spillovers A Figment of Specification Error," Journal of Monetary Economics, 36(1), 165188.

(2002): "Aggregate Productivity and Aggregate Technology," European Economic Review, 46, 963-991.

Brown, D., And J. EARLe (2008): "Understanding the Contributions of Reallocation to Productivity Growth: Lessons from a Comparative Firm-Level Analysis," IZA Discussion Paper \#3683, http://ftp.iza.org/dp3683.pdf.

Bruno, M. (1978): "Duality, Intermediate Inputs and Value-Added," in Production Economics: A Dual Approach to Theory and Applications, ed. by M. Fuss, and D. McFadden. North-Holland. 
Burnside, C., M. Eichenbaum, and S. Rebelo (1995): "Capital Utilization and Returns to Scale," NBER Working Paper \#5125.

Davis, S., J. Haltiwanger, and S. Schuh (1996): Job Creation and Destruction. MIT Press.

Dunne, T., And M. Roberts (1993): "The Long-Run Demand for Labor: Estimates from Census Establishment Data," Census Bureau Center for Economic Studies Discussion Paper CES-93-13.

Foster, L., J. Haltiwanger, and N. Kim (2006): "Gross Job Flows for the U.S. Manufacturing Sector: Measurement from the Longitudinal Research Database," Center for Economic Studies Discussion Paper CES 06-30.

Foster, L., J. Haltiwanger, and C. Krizan (2001): New Developments in Productivity Analysischap. Aggregate Productivity Growth: Lessons from Microeconomic Evidence, pp. 303-372. University of Chicago Press.

Foster, L., J. Haltiwanger, and C. Syverson (2008): "Reallocation, Firm Turnover, and Efficiency: Selection on Productivity or Profitability?," American Ecnomic Review.

Hall, R. (1988): "The Relation Between Price and Marginal Cost in U.S. Industry," Journal of Political Economy, 96, 921-947.

- (1990): "Invariance Properties of Solow's Productivity Residual," in Growth/Productivity/Employment: Essays to Celebrate Bob Solow's Birthday, ed. by P. Diamon. MIT Press.

Hsieh, C.-T., ANd P. J. Klenow (2007): "Misallocation and manufacturing TFP in China and India," NBER Working Paper \#13290, National Bureau of Economic Research.

Hulten, C. (1978): "Growth Accounting with Intermediate Inputs," The Review of Economic Studies, 45(3), 511-518.

Jarmin, R., And J. Miranda (2002): "The Longitudinal Business Database," Census Bureau Center for Economic Studies Discussion Paper CES-02-17. 
Kwon, H. U., F. Narita, and M. Narita (2009): "New Evidence on Japan's Productivity Growth in the 1990s," Working Paper.

LEe, Y. (2005): "The Importance of Reallocations in Cyclical Productivity and Returns to Scale: Evidence from Plant-Level Data," Cleveland Fed Working Paper.

Levinsohn, and Petrin (2003): "Estimating Production Functions Using Inputs to Control for Unobservables," Review of Economic Studies.

Olley, S., And A. Pakes (1996): "The Dynamics of Productivity in the Telecommunications Equipment Industry," Econometrica, 64(6), 12631298 .

Petrin, A., And J. Levinsohn (2008): "Measuring Aggregate Productivity Growth Using Plant-Level Data," Working Paper.

Rotemberg, J. J., And M. Woodford (1995): "Dynamic General Equilibrium Models with Imperfectly Competitive Product Markets," in Frontiers of Business Cycle Research, ed. by T. F. Cooley. Princeton University Press.

Solow, R. M. (1957): "Technical Change and the Aggregate Production Function," Review of Economics and Statistics, 39(3), 312-320.

Wooldridge, J. (2005): "On Estimating Firm-Level Production Functions Using Proxy Variables to Control for Unobservables," Working Paper. 
Table 1: Percentage Growth Rates of Real GDP and Real Value-Added in Manufacturing, 1977-1996

\begin{tabular}{|c|c|c|c|c|c|}
\hline \multirow[b]{5}{*}{ Year } & \multirow{3}{*}{ (1) } & \multicolumn{4}{|c|}{ Real Value-Added in Manufacturing } \\
\hline & & $(2)$ & $(3)$ & $(4)$ & $(5)$ \\
\hline & & & & Plant-level & Plant-level \\
\hline & Real & From & NBER-CES & ASM & ASM \\
\hline & GDP & NIPA & aggregates & (all) & (continuers) \\
\hline 1977 & 4.5 & $\mathrm{n} / \mathrm{a}$ & 5.6 & 6.1 & 6.2 \\
\hline 1978 & 5.0 & $\mathrm{n} / \mathrm{a}$ & 5.2 & 4.7 & 5.5 \\
\hline 1979 & 0.3 & $\mathrm{n} / \mathrm{a}$ & 3.8 & 3.3 & 6.4 \\
\hline 1980 & -4.1 & $\mathrm{n} / \mathrm{a}$ & -4.5 & -6.0 & -6.2 \\
\hline 1981 & 1.7 & $\mathrm{n} / \mathrm{a}$ & 1.9 & 0.8 & 2.7 \\
\hline 1982 & -2.0 & $\mathrm{n} / \mathrm{a}$ & -3.5 & -7.2 & -8.0 \\
\hline 1983 & 5.3 & $\mathrm{n} / \mathrm{a}$ & 3.6 & 3.1 & 5.9 \\
\hline 1984 & 6.6 & $\mathrm{n} / \mathrm{a}$ & 5.8 & 11.0 & 8.6 \\
\hline 1985 & 3.6 & $\mathrm{n} / \mathrm{a}$ & 2.2 & -0.3 & 0.5 \\
\hline 1986 & 3.8 & $\mathrm{n} / \mathrm{a}$ & 0.5 & -0.3 & -0.3 \\
\hline 1987 & 2.5 & $\mathrm{n} / \mathrm{a}$ & 9.2 & 7.0 & 6.7 \\
\hline 1988 & 3.4 & 5.7 & 4.2 & 4.0 & 5.1 \\
\hline 1989 & 2.5 & 1.3 & -0.9 & 4.5 & -0.7 \\
\hline 1990 & 0.4 & -1.1 & -0.7 & -1.5 & -3.1 \\
\hline 1991 & -0.8 & -1.4 & -2.3 & -3.9 & -2.4 \\
\hline 1992 & 2.6 & 3.3 & 7.2 & 9.9 & 3.4 \\
\hline 1993 & 2.0 & 4.2 & 3.4 & -1.4 & 1.9 \\
\hline 1994 & 3.6 & 7.7 & 8.5 & 11.7 & 6.9 \\
\hline 1995 & 1.7 & 4.5 & 11.1 & 12.0 & 4.7 \\
\hline 1996 & 2.6 & 3.7 & 12.3 & 12.5 & 2.9 \\
\hline Mean & 2.5 & 3.1 & 3.6 & 3.5 & 2.3 \\
\hline std. dev. & 2.4 & 3.0 & 4.7 & 6.0 & 4.6 \\
\hline \multicolumn{6}{|c|}{ Correlations of Growth Rates } \\
\hline & GDP & NIPA MFG & NBER & All ASM plants & \\
\hline ASM continuers & 0.78 & 0.97 & 0.78 & 0.79 & \\
\hline
\end{tabular}


Table 2: Percentage Growth Rates of Value-Added,

Primary Input Costs and Aggregate Productivity in U.S. Manufacturing, 1977-1996.

\begin{tabular}{|c|c|c|c|c|c|}
\hline & (1) & $(2)$ & (3) & (4) & $(5)$ \\
\hline Year & $\begin{array}{c}\text { Value } \\
\text { Added }\end{array}$ & $\begin{array}{l}\text { Production } \\
\text { labor costs }\end{array}$ & $\begin{array}{c}\text { Non-production } \\
\text { labor costs }\end{array}$ & $\begin{array}{c}\text { Capital } \\
\text { costs }\end{array}$ & $\begin{array}{c}\text { Aggregate } \\
\text { Productivity } \\
\text { (PL_APG) }\end{array}$ \\
\hline 1977 & 6.2 & 1.1 & 0.4 & 0.3 & 4.3 \\
\hline 1978 & 5.5 & 0.9 & 0.5 & 0.4 & 3.6 \\
\hline 1979 & 6.4 & 0.0 & 0.5 & 0.4 & 5.3 \\
\hline 1980 & -6.2 & -2.1 & 0.6 & 0.4 & -5.1 \\
\hline 1981 & 2.7 & -0.5 & -0.0 & 0.5 & 2.7 \\
\hline 1982 & -8.0 & -3.6 & -0.4 & 0.5 & -4.5 \\
\hline 1983 & 5.9 & 0.0 & -0.4 & 0.3 & 5.9 \\
\hline 1984 & 8.6 & 1.4 & 0.2 & 0.1 & 6.8 \\
\hline 1985 & 0.5 & -0.5 & 0.3 & 0.4 & 0.3 \\
\hline 1986 & -0.3 & -0.6 & 0.1 & 0.4 & -0.3 \\
\hline 1987 & 6.7 & 0.0 & -0.3 & 0.3 & 6.7 \\
\hline 1988 & 5.1 & 0.4 & 0.0 & 0.3 & 4.4 \\
\hline 1989 & -0.7 & -0.2 & 0.0 & 0.3 & -0.9 \\
\hline 1990 & -3.1 & -0.7 & -0.2 & 0.4 & -2.5 \\
\hline 1991 & -2.4 & -0.8 & -0.1 & 0.4 & -2.0 \\
\hline 1992 & 3.4 & -0.0 & -0.5 & 0.2 & 3.7 \\
\hline 1993 & 1.9 & 0.0 & -0.3 & 0.3 & 1.9 \\
\hline 1994 & 6.9 & 0.4 & -0.2 & 0.2 & 6.5 \\
\hline 1995 & 4.7 & 0.0 & 0.0 & 0.3 & 4.2 \\
\hline 1996 & 2.9 & 0.0 & -0.1 & 0.5 & 2.5 \\
\hline Mean & 2.3 & -0.2 & 0.0 & 0.3 & 2.2 \\
\hline s.d. & 4.6 & 1.1 & 0.3 & 0.1 & 3.7 \\
\hline
\end{tabular}


Table 3: Aggregate Productivity Growth Decomposition Technical Efficiency and Reallocation. U.S. Manufacturing 1977-1996

\begin{tabular}{|c|c|c|c|c|c|}
\hline \multirow[b]{7}{*}{ Year } & \multicolumn{5}{|c|}{ Percentage Growth Rates of ... } \\
\hline & \multirow[b]{2}{*}{ (1) } & \multirow[b]{2}{*}{ (2) } & \multicolumn{3}{|c|}{$(2)=(3)+(4)-(5)$} \\
\hline & & & $(3)$ & $(4)$ & $(5)$ \\
\hline & & & & & Fixed \\
\hline & & PL Aggregate & Technical & $\mathrm{PL}$ & Costs + \\
\hline & Value & Productivity & Efficiency & Reallocation & Approximation \\
\hline & Added & (PL_APG) & $(\mathrm{TE})$ & (PL_RE) & Error \\
\hline 1977 & 6.2 & 4.3 & -0.5 & 4.6 & -0.3 \\
\hline 1978 & 5.5 & 3.6 & 1.0 & 2.4 & -0.2 \\
\hline 1979 & 6.4 & 5.4 & 3.1 & 1.0 & -1.3 \\
\hline 1980 & -6.2 & -5.1 & -3.9 & -0.3 & 0.9 \\
\hline 1981 & 2.7 & 2.8 & -0.1 & 1.4 & -1.4 \\
\hline 1982 & -8.0 & -4.5 & -2.9 & -1.4 & 0.2 \\
\hline 1983 & 5.9 & 5.9 & 4.2 & 1.6 & -0.1 \\
\hline 1984 & 8.6 & 6.8 & 1.9 & 4.9 & -0.1 \\
\hline 1985 & 0.5 & 0.3 & -3.5 & 3.5 & -0.4 \\
\hline 1986 & -0.3 & -0.2 & -4.3 & 3.9 & -0.2 \\
\hline 1987 & 6.7 & 6.7 & 3.1 & 2.9 & -0.7 \\
\hline 1988 & 5.1 & 4.4 & 2.1 & 2.4 & 0.0 \\
\hline 1989 & -0.7 & -0.9 & -2.3 & 1.7 & 0.2 \\
\hline 1990 & -3.1 & -2.5 & -0.4 & -1.1 & 0.9 \\
\hline 1991 & -2.5 & -2.0 & -2.7 & 1.9 & 1.2 \\
\hline 1992 & 3.4 & 3.7 & 3.0 & 1.2 & 0.5 \\
\hline 1993 & 1.9 & 1.9 & 0.1 & 2.6 & 0.7 \\
\hline 1994 & 6.9 & 6.5 & 3.9 & 3.0 & 0.4 \\
\hline 1995 & 4.7 & 4.2 & 2.2 & 2.4 & 0.4 \\
\hline 1996 & 2.9 & 2.5 & 0.6 & 3.2 & 1.3 \\
\hline Mean & 2.3 & 2.2 & 0.2 & 2.1 & 0.1 \\
\hline s.d. & 4.6 & 3.7 & 2.7 & 1.7 & 0.7 \\
\hline
\end{tabular}

Gross Output Production Functions estimated by Wooldridge (2005) modification of Levinsohn and Petrin (2003) estimator.

Correlation of Annual Growth Rates

\begin{tabular}{ccc}
\hline & TE & PL_RE \\
PL_APG & 0.86 & 0.61
\end{tabular}


Table 4: Decomposition of Reallocation Term (equation 11): U.S. Manufacturing, 1977-1996

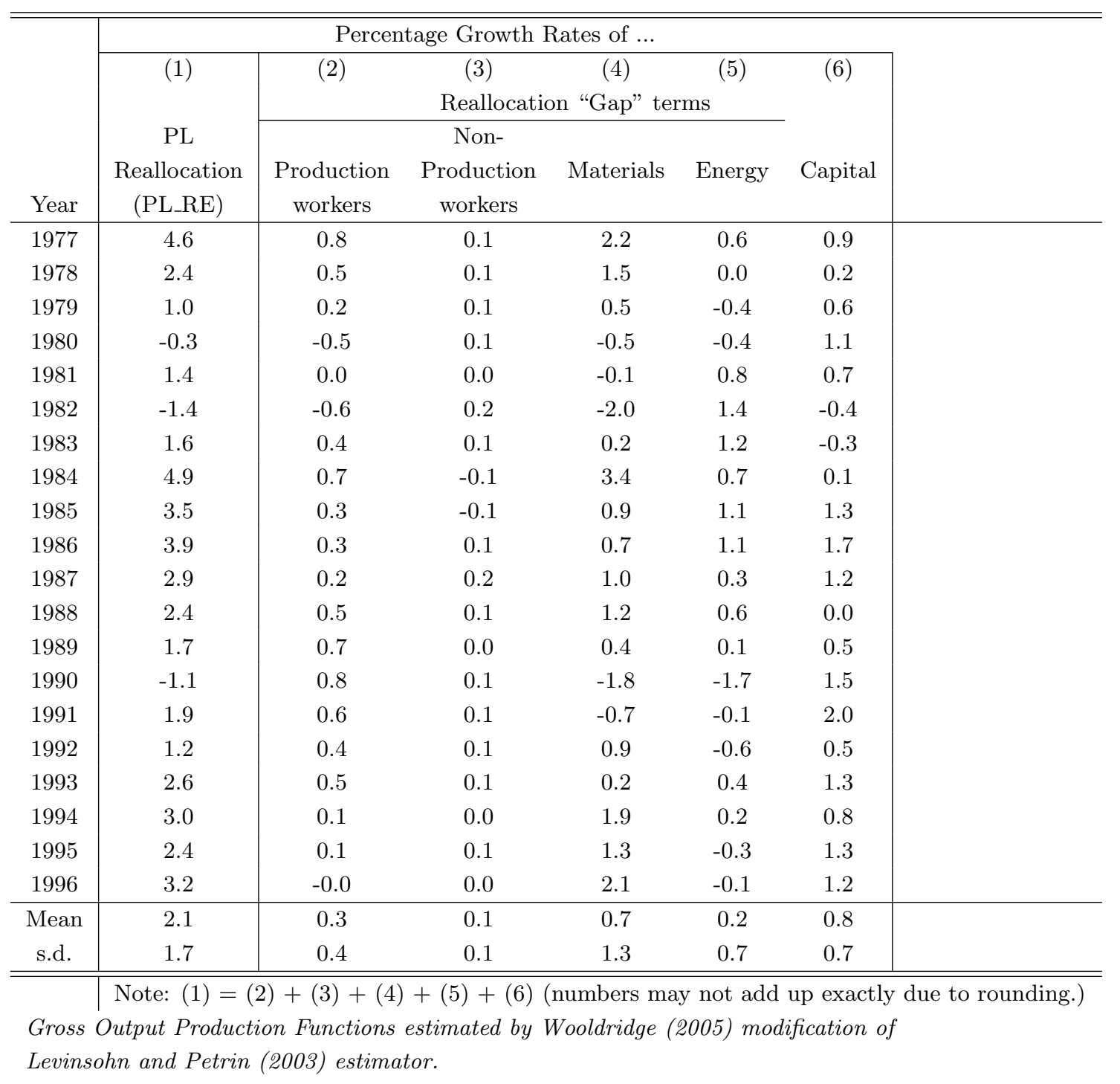


Table 5: Aggregate Productivity Growth Decomposition Technical Efficiency and Reallocation. U.S. Manufacturing 1977-1999 (Value-Added Production Functions)

\begin{tabular}{|c|c|c|c|c|}
\hline \multirow[b]{6}{*}{ Year } & \multicolumn{4}{|c|}{ Percentage Growth Rates of ... } \\
\hline & \multirow{3}{*}{$(1)$} & \multirow{3}{*}{$\begin{array}{c}(2) \\
\text { PL Aggregate }\end{array}$} & \multicolumn{2}{|c|}{ PL_APG $=$ TE+PL_RE } \\
\hline & & & $(3)$ & $(4)$ \\
\hline & & & Technical & PL \\
\hline & Value & Productivity & Efficiency & Reallocation \\
\hline & Added & $\left(\mathrm{PL} \_\mathrm{APG}\right)$ & $(\mathrm{TE})$ & (PL_RE) \\
\hline 1977 & 5.4 & 4.2 & 3.9 & 0.3 \\
\hline 1978 & 5.0 & 3.7 & 2.8 & 0.9 \\
\hline 1979 & 4.4 & 3.8 & 3.3 & 0.5 \\
\hline 1980 & -4.6 & -3.4 & -3.9 & 0.5 \\
\hline 1981 & 2.5 & 2.7 & 1.7 & 1.0 \\
\hline 1982 & -6.0 & -2.4 & -2.1 & -0.3 \\
\hline 1983 & 5.8 & 5.9 & 5.6 & 0.3 \\
\hline 1984 & 4.4 & 3.2 & 2.3 & 0.9 \\
\hline 1985 & 3.4 & 3.3 & 1.8 & 1.5 \\
\hline 1986 & 0.3 & 0.5 & -0.9 & 1.4 \\
\hline 1987 & 5.4 & 5.5 & 4.4 & 1.0 \\
\hline 1988 & 4.5 & 4.0 & 2.9 & 1.0 \\
\hline 1989 & -0.2 & -0.1 & -1.0 & 0.9 \\
\hline 1990 & -2.1 & -1.8 & -3.0 & 1.2 \\
\hline 1991 & -1.1 & -0.5 & -1.7 & 1.2 \\
\hline 1992 & 2.7 & 3.2 & 1.9 & 1.3 \\
\hline 1993 & 1.6 & 1.7 & 0.6 & 1.1 \\
\hline 1994 & 4.3 & 3.9 & 3.3 & 0.7 \\
\hline 1995 & 5.2 & 4.8 & 3.1 & 1.7 \\
\hline 1996 & 2.6 & 2.2 & 0.2 & 2.0 \\
\hline 1997 & 8.4 & 6.6 & 5.0 & 1.6 \\
\hline 1998 & 5.8 & 5.5 & 3.9 & 1.6 \\
\hline 1999 & 4.7 & 4.5 & 3.4 & 1.1 \\
\hline Mean & 2.7 & 2.7 & 1.6 & 1.0 \\
\hline s.d. & 3.5 & 2.7 & 2.6 & 0.5 \\
\hline
\end{tabular}

Value-added Production Functions estimated by Wooldrige (2005) modification of Levinsohn and Petrin (2003) estimator. 
Table 6: Decomposition of Reallocation Term (equation 12):

U.S. Manufacturing, 1977-1999

(Value-Added Production Functions)

\begin{tabular}{|c|c|c|c|c|c|}
\hline \multirow[b]{3}{*}{ Year } & \multicolumn{5}{|c|}{ Percentage Growth Rates of ... } \\
\hline & $(1)$ & $(2)$ & $(3)$ & $(4)$ & $(5)$ \\
\hline & $\begin{array}{l}\text { Value } \\
\text { Added }\end{array}$ & $\begin{array}{c}\text { PL } \\
\text { Reallocation } \\
\left(\mathrm{PL} \_\mathrm{RE}\right)\end{array}$ & $\begin{array}{l}\text { Production } \\
\text { worker } \\
\text { "gap" term }\end{array}$ & $\begin{array}{c}\text { Non- } \\
\text { Production } \\
\text { worker } \\
\text { "gap" term }\end{array}$ & $\begin{array}{l}\text { Capital } \\
\text { "gap" term }\end{array}$ \\
\hline 1977 & 5.4 & 0.3 & 0.4 & 0.2 & -0.3 \\
\hline 1978 & 5.0 & 0.9 & 0.5 & 0.2 & 0.2 \\
\hline 1979 & 4.4 & 0.5 & 0.1 & 0.1 & 0.3 \\
\hline 1980 & -4.6 & 0.5 & -0.4 & 0.1 & 0.8 \\
\hline 1981 & 2.5 & 1.0 & 0.1 & 0.0 & 0.9 \\
\hline 1982 & -6.0 & -0.3 & -1.0 & 0.0 & 0.7 \\
\hline 1983 & 5.8 & 0.3 & -0.3 & 0.0 & 0.7 \\
\hline 1984 & 4.4 & 0.9 & 0.4 & -0.1 & 0.6 \\
\hline 1985 & 3.4 & 1.5 & 0.1 & 0.1 & 1.4 \\
\hline 1986 & 0.3 & 1.4 & 0.1 & 0.1 & 1.2 \\
\hline 1987 & 5.4 & 1.0 & 0.1 & 0.1 & 0.8 \\
\hline 1988 & 4.5 & 1.0 & 0.3 & 0.0 & 0.7 \\
\hline 1989 & -0.2 & 0.9 & 0.1 & 0.1 & 0.7 \\
\hline 1990 & -2.1 & 1.2 & -0.3 & 0.1 & 1.4 \\
\hline 1991 & -1.1 & 1.2 & -0.2 & 0.2 & 1.2 \\
\hline 1992 & 2.7 & 1.3 & 0.1 & 0.0 & 1.2 \\
\hline 1993 & 1.6 & 1.1 & -0.2 & 0.0 & 1.3 \\
\hline 1994 & 4.3 & 0.7 & 0.0 & -0.3 & 1.0 \\
\hline 1995 & 5.2 & 1.7 & 0.0 & 0.1 & 1.5 \\
\hline 1996 & 2.6 & 2.0 & 0.1 & 0.1 & 1.8 \\
\hline 1997 & 8.4 & 1.6 & 0.2 & 0.0 & 1.4 \\
\hline 1998 & 5.8 & 1.6 & -0.2 & 0.0 & 1.9 \\
\hline 1999 & 4.7 & 1.1 & 0.0 & 0.1 & 1.1 \\
\hline Mean & 2.7 & 1.0 & 0.0 & 0.0 & 1.0 \\
\hline s.d. & 3.5 & 0.5 & 0.3 & 0.1 & 0.5 \\
\hline
\end{tabular}

Value-added Production functions estimated by Wooldridge (2005), modification of Levinsohn and Petrin (2003) estimator. 
Table A1: Growth Rates of Real GDP and Real Value-Added in Manufacturing, 1977-1999

\begin{tabular}{|c|c|c|c|}
\hline Year & $\begin{array}{c}\% \text { Growth in } \\
\text { Real GDP }\end{array}$ & $\begin{array}{c}\% \text { Growth in } \\
\text { Real Value-Added } \\
\text { In Manufacturing } \\
\text { (from ASM) }\end{array}$ & $\begin{array}{c}\text { Manufacturing } \\
\text { Value-Added Share } \\
\text { of GDP (levels, } \\
\text { from NIPA) }\end{array}$ \\
\hline 1977 & 4.5 & 5.4 & 0.21 \\
\hline 1978 & 5.0 & 5.0 & 0.22 \\
\hline 1979 & 0.3 & 4.4 & 0.21 \\
\hline 1980 & 4.1 & -4.6 & 0.21 \\
\hline 1981 & 1.7 & 2.5 & 0.20 \\
\hline 1982 & -2.0 & -6.0 & 0.19 \\
\hline 1983 & 5.3 & 5.8 & 0.18 \\
\hline 1984 & 6.6 & 4.4 & 0.18 \\
\hline 1985 & 3.6 & 3.4 & 0.18 \\
\hline 1986 & 3.8 & 0.3 & 0.17 \\
\hline 1987 & 2.5 & 5.4 & 0.17 \\
\hline 1988 & 3.4 & 4.5 & 0.17 \\
\hline 1989 & 2.5 & -0.2 & 0.17 \\
\hline 1990 & 0.4 & -2.1 & 0.16 \\
\hline 1991 & -0.8 & -1.1 & 0.16 \\
\hline 1992 & 2.6 & 2.7 & 0.16 \\
\hline 1993 & 2.0 & 1.6 & 0.16 \\
\hline 1994 & 3.6 & 4.3 & 0.16 \\
\hline 1995 & 1.7 & 5.2 & 0.16 \\
\hline 1996 & 2.6 & 2.6 & 0.15 \\
\hline 1997 & 3.9 & 8.4 & 0.15 \\
\hline 1998 & 3.7 & 5.8 & 0.15 \\
\hline 1999 & 3.7 & 4.7 & 0.15 \\
\hline Mean & 2.5 & 2.7 & \\
\hline std. dev. & 2.4 & 3.5 & \\
\hline
\end{tabular}

Note: This table uses the value-added sample used in Tables 5-6.

Source: Bureau of Economic Analysis, Annual Survey of Manufacure and authors' calculations. 
Table A2: Growth Rates of Value Added,

Primary Input Costs, and Aggregate Productivity

in U.S. Manufacturing, 1977-1999

\begin{tabular}{|c|c|c|c|c|c|}
\hline \multirow[b]{2}{*}{ Year } & \multicolumn{5}{|c|}{ Percentage Growth Rates of ... } \\
\hline & $\begin{array}{l}\text { Value } \\
\text { Added }\end{array}$ & $\begin{array}{l}\text { Production } \\
\text { labor costs }\end{array}$ & $\begin{array}{c}\text { Non-production } \\
\text { labor costs }\end{array}$ & $\begin{array}{c}\text { Capital } \\
\text { costs }\end{array}$ & $\begin{array}{c}\text { Aggregate } \\
\text { Productivity } \\
\text { (PL_APG) }\end{array}$ \\
\hline 1977 & 5.4 & 1.0 & 0.4 & -0.2 & 4.2 \\
\hline 1978 & 5.0 & 0.8 & 0.5 & 0.0 & 3.7 \\
\hline 1979 & 4.4 & 0.0 & 0.4 & 0.1 & 3.8 \\
\hline 1980 & -4.6 & -2.0 & 0.6 & 0.2 & -3.4 \\
\hline 1981 & 2.5 & -0.5 & 0.0 & 0.3 & 2.7 \\
\hline 1982 & -6.0 & -3.5 & -0.4 & 0.3 & -2.4 \\
\hline 1983 & 5.8 & 0.0 & -0.2 & 0.1 & 5.9 \\
\hline 1984 & 4.4 & 1.0 & 0.2 & 0.0 & 3.2 \\
\hline 1985 & 3.4 & -0.5 & 0.3 & 0.2 & 3.3 \\
\hline 1986 & 0.3 & -0.6 & 0.1 & 0.3 & 0.5 \\
\hline 1987 & 5.4 & 0.0 & -0.2 & 0.2 & 5.5 \\
\hline 1988 & 4.5 & 0.3 & 0.1 & 0.1 & 4.0 \\
\hline 1989 & -0.2 & -0.2 & 0.0 & 0.1 & -0.1 \\
\hline 1990 & -2.1 & -0.6 & 0.0 & 0.3 & -1.8 \\
\hline 1991 & -1.1 & -0.8 & -0.1 & 0.3 & -0.5 \\
\hline 1992 & 2.7 & -0.1 & -0.5 & 0.2 & 3.2 \\
\hline 1993 & 1.6 & 0.0 & -0.3 & 0.2 & 1.7 \\
\hline 1994 & 4.3 & 0.3 & -0.1 & 0.2 & 3.9 \\
\hline 1995 & 5.2 & 0.1 & 0.0 & 0.3 & 4.8 \\
\hline 1996 & 2.6 & 0.0 & -0.1 & 0.5 & 2.2 \\
\hline 1997 & 8.4 & 0.1 & 0.4 & 1.4 & 6.6 \\
\hline 1998 & 5.8 & -0.2 & 0.0 & 0.4 & 5.5 \\
\hline 1999 & 4.7 & -0.1 & 0.0 & 0.3 & 4.5 \\
\hline Mean & 2.7 & -0.2 & 0.1 & 0.3 & 2.7 \\
\hline s.d. & 3.5 & 0.9 & 0.3 & 0.3 & 2.7 \\
\hline
\end{tabular}

Note: This table uses the value-added sample used in tables 5-6. 
Table A3a: Aggregate Productivity Growth Decomposition Technical Efficiency and Reallocation. U.S. Manufacturing 1977-1996

\begin{tabular}{|c|c|c|c|c|}
\hline \multirow[b]{6}{*}{ Year } & \multicolumn{4}{|c|}{ Percentage Growth Rates of ... } \\
\hline & \multirow[b]{2}{*}{$(1)$} & \multirow{3}{*}{$\begin{array}{c}(2) \\
\text { PL Aggregate }\end{array}$} & \multicolumn{2}{|c|}{$\mathrm{PL} \_\mathrm{APG}=\mathrm{TE}+\mathrm{PL} \_\mathrm{RE}$} \\
\hline & & & (3) & $(4)$ \\
\hline & & & Technical & PL \\
\hline & Value & Productivity & Efficiency & Reallocation \\
\hline & Added & (PL_APG) & $(\mathrm{TE})$ & (PL_RE) \\
\hline 1977 & 6.2 & 4.3 & 0.8 & 3.4 \\
\hline 1978 & 5.5 & 3.6 & 0.4 & 3.1 \\
\hline 1979 & 6.4 & 5.4 & 1.4 & 2.6 \\
\hline 1980 & -6.2 & -5.1 & -5.3 & 0.7 \\
\hline 1981 & 2.7 & 2.8 & -0.1 & 1.6 \\
\hline 1982 & -8.0 & -4.5 & -4.1 & -0.8 \\
\hline 1983 & 5.9 & 5.9 & 4.8 & 1.2 \\
\hline 1984 & 8.6 & 6.8 & 3.3 & 3.9 \\
\hline 1985 & 0.5 & 0.3 & -2.4 & 2.2 \\
\hline 1986 & -0.3 & -0.2 & -2.4 & 1.8 \\
\hline 1987 & 6.7 & 6.7 & 4.1 & 1.9 \\
\hline 1988 & 5.1 & 4.4 & 2.4 & 2.3 \\
\hline 1989 & -0.7 & -0.9 & -2.1 & 1.4 \\
\hline 1990 & -3.1 & -2.5 & -2.4 & 0.7 \\
\hline 1991 & -2.5 & -2.0 & -2.0 & 1.1 \\
\hline 1992 & 3.4 & 3.7 & 2.7 & 1.5 \\
\hline 1993 & 1.9 & 1.9 & 1.3 & 1.5 \\
\hline 1994 & 6.9 & 6.5 & 5.1 & 2.0 \\
\hline 1995 & 4.7 & 4.2 & 2.1 & 2.5 \\
\hline 1996 & 2.9 & 2.5 & 0.7 & 3.0 \\
\hline Mean & 2.3 & 2.2 & 0.4 & 1.9 \\
\hline s.d. & 4.6 & 3.7 & 3.0 & 1.1 \\
\hline
\end{tabular}

Gross Output Production Functions estimated by Levinsohn and Petrin (2003) estimator. 
Table A3b: Aggregate Productivity Growth Decomposition Technical Efficiency and Reallocation. U.S. Manufacturing 1977-1996

\begin{tabular}{|c|c|c|c|c|}
\hline \multirow[b]{6}{*}{ Year } & \multicolumn{4}{|c|}{ Percentage Growth Rates of ... } \\
\hline & \multirow[b]{2}{*}{ (1) } & \multirow{5}{*}{$\begin{array}{c}(2) \\
\text { PL Aggregate } \\
\text { Productivity } \\
\text { (PL_APG) }\end{array}$} & \multicolumn{2}{|c|}{$\mathrm{PL} \_\mathrm{APG}=\mathrm{TE}+\mathrm{PL} \_\mathrm{RE}$} \\
\hline & & & $(3)$ & $(4)$ \\
\hline & & & Technical & PL \\
\hline & Value & & Efficiency & \\
\hline & Added & & $(\mathrm{TE})$ & (PL_RE) \\
\hline 1977 & 6.2 & 4.3 & 0.6 & 3.7 \\
\hline 1978 & 5.5 & 3.6 & 0.5 & 3.1 \\
\hline 1979 & 6.4 & 5.4 & 2.0 & 3.4 \\
\hline 1980 & -6.2 & -5.1 & -3.9 & -1.2 \\
\hline 1981 & 2.7 & 2.8 & -0.3 & 3.1 \\
\hline 1982 & -8.0 & -4.5 & -3.0 & -1.5 \\
\hline 1983 & 5.9 & 5.9 & 4.4 & 1.5 \\
\hline 1984 & 8.6 & 6.8 & 2.4 & 4.4 \\
\hline 1985 & 0.5 & 0.3 & -2.0 & 2.3 \\
\hline 1986 & -0.3 & -0.2 & -2.3 & 2.0 \\
\hline 1987 & 6.7 & 6.7 & 4.2 & 2.4 \\
\hline 1988 & 5.1 & 4.4 & 1.9 & 2.5 \\
\hline 1989 & -0.7 & -0.9 & -1.7 & 0.8 \\
\hline 1990 & -3.1 & -2.5 & -1.4 & -1.1 \\
\hline 1991 & -2.5 & -2.0 & -1.5 & -0.5 \\
\hline 1992 & 3.4 & 3.7 & 2.9 & 0.8 \\
\hline 1993 & 1.9 & 1.9 & 1.3 & 0.6 \\
\hline 1994 & 6.9 & 6.5 & 4.7 & 1.8 \\
\hline 1995 & 4.7 & 4.2 & 2.4 & 1.8 \\
\hline 1996 & 2.9 & 2.5 & 1.6 & 0.9 \\
\hline Mean & 2.3 & 2.2 & 0.6 & 1.6 \\
\hline s.d. & 4.6 & 3.7 & 2.6 & 1.7 \\
\hline
\end{tabular}


Table A4a: Decomposition of Reallocation Term (equation 11):

U.S. Manufacturing, 1977-1996

\begin{tabular}{|c|c|c|c|c|c|}
\hline \multirow[b]{5}{*}{ Year } & \multicolumn{5}{|c|}{ Percentage Growth Rates of ... } \\
\hline & \multirow{4}{*}{$\begin{array}{c}\text { PL } \\
\text { Reallocation } \\
(\text { PL_RE })\end{array}$} & $(2)$ & $(3)$ & $(4)$ & $(5)$ \\
\hline & & \multicolumn{4}{|c|}{ Reallocation "Gap" terms } \\
\hline & & \multicolumn{3}{|c|}{ Non- } & \multirow[b]{2}{*}{ Capital } \\
\hline & & $\begin{array}{c}\text { Production } \\
\text { workers }\end{array}$ & $\begin{array}{c}\text { Production } \\
\text { workers }\end{array}$ & Materials & \\
\hline 1977 & 3.4 & 0.8 & 0.2 & 1.5 & 0.8 \\
\hline 1978 & 3.1 & 0.7 & 0.2 & 1.0 & 1.2 \\
\hline 1979 & 2.6 & 0.1 & 0.2 & 1.0 & 1.4 \\
\hline 1980 & 0.7 & -1.1 & 0.1 & 0.1 & 1.6 \\
\hline 1981 & 1.6 & 0.1 & -0.0 & -0.1 & 1.5 \\
\hline 1982 & -0.8 & -1.5 & 0.1 & -0.7 & 1.4 \\
\hline 1983 & 1.2 & 0.2 & 0.1 & -0.1 & 1.0 \\
\hline 1984 & 3.9 & 0.8 & -0.0 & 2.3 & 0.8 \\
\hline 1985 & 2.2 & 0.1 & 0.0 & 0.6 & 1.5 \\
\hline 1986 & 1.8 & -0.1 & 0.1 & 0.4 & 1.3 \\
\hline 1987 & 1.9 & 0.1 & 0.2 & 0.6 & 1.0 \\
\hline 1988 & 2.3 & 0.5 & 0.1 & 0.8 & 0.8 \\
\hline 1989 & 1.4 & 0.2 & 0.1 & 0.4 & 0.7 \\
\hline 1990 & 0.7 & -0.6 & 0.0 & -0.2 & 1.4 \\
\hline 1991 & 1.1 & -0.2 & 0.2 & -0.4 & 1.5 \\
\hline 1992 & 1.5 & 0.3 & -0.0 & 0.4 & 0.8 \\
\hline 1993 & 1.5 & 0.2 & 0.1 & 0.3 & 1.0 \\
\hline 1994 & 2.0 & 0.3 & 0.0 & 0.8 & 0.8 \\
\hline 1995 & 2.5 & 0.0 & 0.2 & 1.2 & 1.1 \\
\hline 1996 & 3.0 & 0.2 & 0.0 & 1.7 & 1.0 \\
\hline Mean & 1.9 & 0.1 & 0.1 & 0.6 & 1.1 \\
\hline s.d. & 1.1 & 0.6 & 0.1 & 0.7 & 0.3 \\
\hline & Note: $(1)=$ & $+(3)+(4)$ & $+(5)$ (numb & s may no & y due \\
\hline
\end{tabular}


Table A4b: Decomposition of Reallocation Term (equation 11):

U.S. Manufacturing, 1977-1996

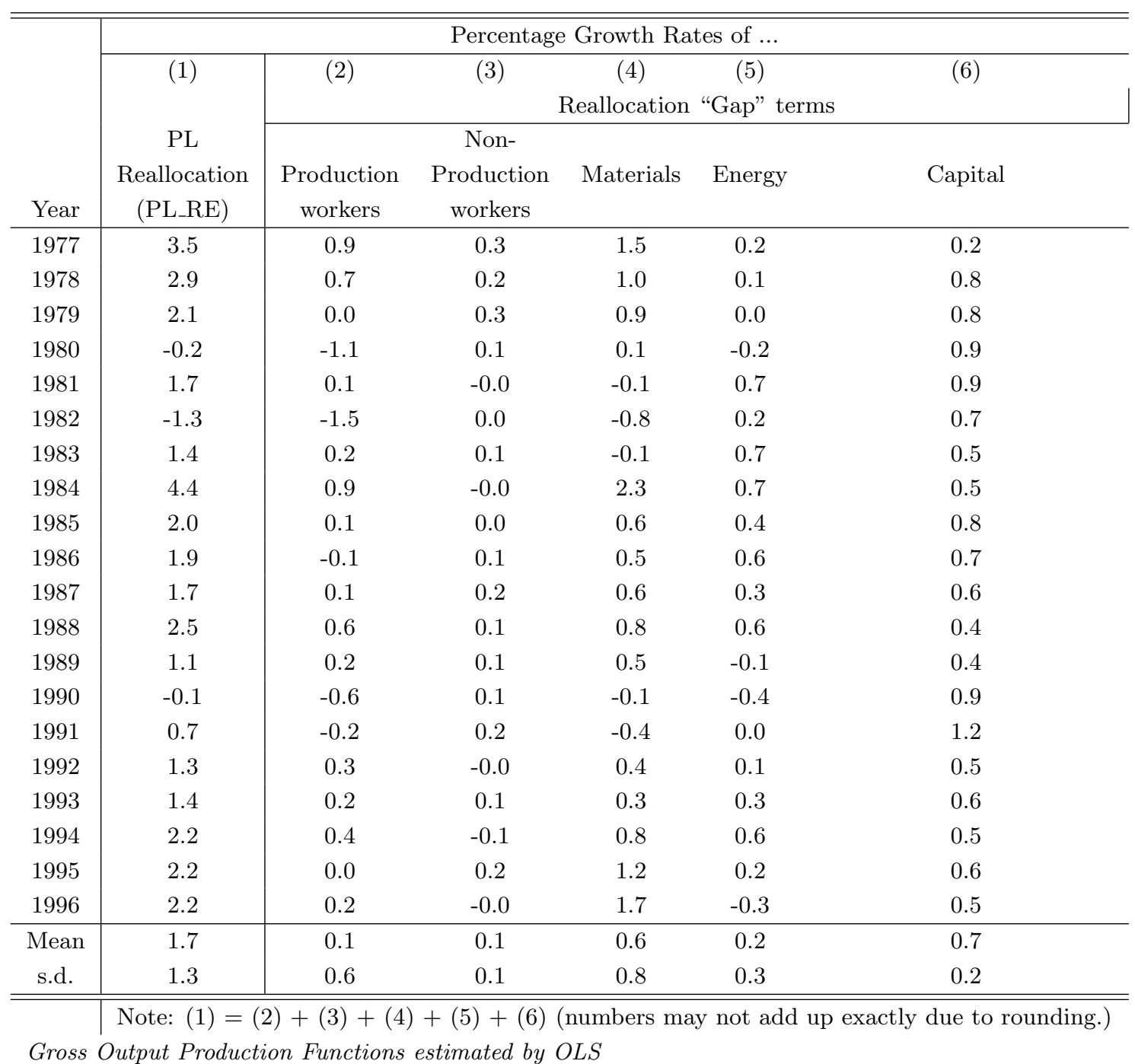


Table A5a: Aggregate Productivity Growth Decomposition Technical Efficiency and Reallocation. U.S. Manufacturing 1977-1999

\begin{tabular}{|c|c|c|c|c|}
\hline \multirow[b]{6}{*}{ Year } & \multicolumn{4}{|c|}{ Percentage Growth Rates of ... } \\
\hline & \multirow{3}{*}{ (1) } & \multirow{3}{*}{$\begin{array}{c}(2) \\
\text { PL Aggregate }\end{array}$} & \multicolumn{2}{|c|}{ PL_APG $=$ TE $+P L \_R E$} \\
\hline & & & $(3)$ & $(4)$ \\
\hline & & & Technical & $\mathrm{PL}$ \\
\hline & Value & Productivity & Efficiency & Reallocation \\
\hline & Added & (PL_APG) & $(\mathrm{TE})$ & (PL_RE) \\
\hline 1977 & 5.4 & 4.2 & 3.8 & 0.4 \\
\hline 1978 & 5.0 & 3.7 & 2.8 & 0.9 \\
\hline 1979 & 4.4 & 3.8 & 3.2 & 0.6 \\
\hline 1980 & -4.6 & -3.4 & -3.8 & 0.4 \\
\hline 1981 & 2.5 & 2.7 & 1.8 & 0.9 \\
\hline 1982 & -6.0 & -2.4 & -1.9 & -0.4 \\
\hline 1983 & 5.8 & 5.9 & 5.6 & 0.3 \\
\hline 1984 & 4.4 & 3.2 & 2.3 & 0.9 \\
\hline 1985 & 3.4 & 3.3 & 1.9 & 1.4 \\
\hline 1986 & 0.3 & 0.5 & -0.9 & 1.3 \\
\hline 1987 & 5.4 & 5.5 & 4.5 & 1.0 \\
\hline 1988 & 4.5 & 4.0 & 3.0 & 1.0 \\
\hline 1989 & -0.2 & -0.1 & -0.9 & 0.8 \\
\hline 1990 & -2.1 & -1.8 & -2.9 & 1.1 \\
\hline 1991 & -1.1 & -0.5 & -1.6 & 1.1 \\
\hline 1992 & 2.7 & 3.2 & 1.8 & 1.3 \\
\hline 1993 & 1.6 & 1.7 & 0.7 & 0.9 \\
\hline 1994 & 4.3 & 3.9 & 3.2 & 0.7 \\
\hline 1995 & 5.2 & 4.8 & 3.0 & 1.8 \\
\hline 1996 & 2.6 & 2.2 & 0.2 & 2.0 \\
\hline 1997 & 8.4 & 6.6 & 4.8 & 1.8 \\
\hline 1998 & 5.8 & 5.5 & 4.0 & 1.5 \\
\hline 1999 & 4.7 & 4.5 & 3.4 & 1.1 \\
\hline Mean & 2.7 & 2.7 & 1.7 & 1.0 \\
\hline s.d. & 3.5 & 2.7 & 2.6 & 0.6 \\
\hline
\end{tabular}

Value-added Production Functions estimated by Levinsohn and Petrin (2003) estimator. 
Table A5b: Aggregate Productivity Growth Decomposition: Technical Efficiency and Reallocation. U.S. Manufacturing, 1977-1999

\begin{tabular}{|c|c|c|c|c|}
\hline \multirow[b]{6}{*}{ Year } & \multicolumn{4}{|c|}{ Percentage Growth Rates of ... } \\
\hline & \multirow[b]{2}{*}{ (1) } & \multirow{5}{*}{$\begin{array}{c}(2) \\
\text { PL Aggregate } \\
\text { Productivity } \\
\text { (PL_APG) }\end{array}$} & \multicolumn{2}{|c|}{ PL_APG $=\mathrm{TE}+\mathrm{PL} \_\mathrm{RE}$} \\
\hline & & & $(3)$ & $(4)$ \\
\hline & & & Technical & PL \\
\hline & Value & & Efficiency & Reallocation \\
\hline & Added & & $(\mathrm{TE})$ & (PL_RE) \\
\hline 1977 & 5.4 & 4.2 & 2.6 & 1.6 \\
\hline 1978 & 5.0 & 3.7 & 1.9 & 1.8 \\
\hline 1979 & 4.4 & 3.8 & 3.0 & 0.8 \\
\hline 1980 & -4.6 & -3.4 & -2.8 & -0.6 \\
\hline 1981 & 2.5 & 2.7 & 2.0 & 0.7 \\
\hline 1982 & -6.0 & -2.4 & 0.1 & -2.5 \\
\hline 1983 & 5.8 & 5.9 & 5.7 & 0.1 \\
\hline 1984 & 4.4 & 3.2 & 1.7 & 1.6 \\
\hline 1985 & 3.4 & 3.3 & 2.0 & 1.3 \\
\hline 1986 & 0.3 & 0.5 & -0.4 & 0.9 \\
\hline 1987 & 5.4 & 5.5 & 4.7 & 0.8 \\
\hline 1988 & 4.5 & 4.0 & 2.7 & 1.3 \\
\hline 1989 & -0.2 & -0.1 & -0.8 & 0.6 \\
\hline 1990 & -2.1 & -1.8 & -2.2 & 0.4 \\
\hline 1991 & -1.1 & -0.5 & -0.8 & 0.3 \\
\hline 1992 & 2.7 & 3.2 & 2.3 & 0.9 \\
\hline 1993 & 1.6 & 1.7 & 1.0 & 0.7 \\
\hline 1994 & 4.3 & 3.9 & 3.1 & 0.8 \\
\hline 1995 & 5.2 & 4.8 & 2.7 & 2.1 \\
\hline 1996 & 2.6 & 2.2 & 0.3 & 1.9 \\
\hline 1997 & 8.4 & 6.6 & 4.9 & 1.7 \\
\hline 1998 & 5.8 & 5.5 & 4.5 & 1.0 \\
\hline 1999 & 4.7 & 4.5 & 3.7 & 0.9 \\
\hline Mean & 2.7 & 2.7 & 1.8 & 0.8 \\
\hline s.d. & 3.5 & 2.7 & 2.2 & 1.0 \\
\hline
\end{tabular}

Value-added Production Functions estimated by OLS. 
Table A6a: Decomposition of Reallocation Term (equation 12): U.S. Manufacturing, 1977-1999

\begin{tabular}{|c|c|c|c|c|c|}
\hline \multirow[b]{6}{*}{ Year } & \multicolumn{5}{|c|}{ Percentage Growth Rates of ... } \\
\hline & (1) & $(2)$ & $(3)$ & $(4)$ & (5) \\
\hline & & & & Non- & \\
\hline & & PL & Production & Production & \\
\hline & Value & Reallocation & worker & worker & Capital \\
\hline & Added & (PL_RE) & "gap" term & "gap" term & "gap" term \\
\hline 1977 & 5.4 & 0.4 & 1.2 & 0.4 & -0.1 \\
\hline 1978 & 5.0 & 0.9 & 1.0 & 0.5 & 0.2 \\
\hline 1979 & 4.4 & 0.6 & 0.1 & 0.5 & 0.3 \\
\hline 1980 & -4.6 & 0.4 & -1.8 & 0.4 & 0.8 \\
\hline 1981 & 2.5 & 0.9 & -0.2 & 0.1 & 0.8 \\
\hline 1982 & -6.0 & -0.4 & -3.0 & -0.1 & 0.6 \\
\hline 1983 & 5.8 & 0.3 & -0.3 & -0.2 & 0.6 \\
\hline 1984 & 4.4 & 0.9 & 1.0 & 0.1 & 0.5 \\
\hline 1985 & 3.4 & 1.4 & -0.2 & 0.3 & 1.2 \\
\hline 1986 & 0.3 & 1.3 & -0.4 & 0.1 & 1.2 \\
\hline 1987 & 5.4 & 1.0 & 0.1 & -0.1 & 0.8 \\
\hline 1988 & 4.5 & 1.0 & 0.6 & 0.1 & 0.6 \\
\hline 1989 & -0.2 & 0.8 & 0.0 & 0.0 & 0.6 \\
\hline 1990 & -2.1 & 1.1 & -1.0 & 0.1 & 1.3 \\
\hline 1991 & -1.1 & 1.1 & -0.9 & 0.1 & 1.1 \\
\hline 1992 & 2.7 & 1.3 & 0.0 & -0.4 & 1.2 \\
\hline 1993 & 1.6 & 0.9 & -0.3 & -0.2 & 1.2 \\
\hline 1994 & 4.3 & 0.7 & 0.3 & -0.3 & 0.9 \\
\hline 1995 & 5.2 & 1.8 & 0.2 & 0.5 & 1.4 \\
\hline 1996 & 2.6 & 2.0 & 0.1 & 0.2 & 1.6 \\
\hline 1997 & 8.4 & 1.8 & 0.3 & 0.4 & 1.0 \\
\hline 1998 & 5.8 & 1.5 & -0.7 & 0.1 & 1.6 \\
\hline 1999 & 4.7 & 1.1 & -0.1 & 0.0 & 1.0 \\
\hline mean & 2.7 & 1.0 & 0.0 & 0.0 & 1.0 \\
\hline s.d. & 3.5 & 0.6 & 0.4 & 0.1 & 0.5 \\
\hline
\end{tabular}

Value-added Production functions estimated by the Levinsohn and Petrin (2003) estimator 
Table A6b: Decomposition of Reallocation Term (equation 12):

U.S. Manufacturing, 1977-1999

\begin{tabular}{|c|c|c|c|c|c|}
\hline \multirow[b]{6}{*}{ Year } & \multicolumn{5}{|c|}{ Percentage Growth Rates of ... } \\
\hline & (1) & $(2)$ & $(3)$ & $(4)$ & $(5)$ \\
\hline & & & & Non- & \\
\hline & & $\mathrm{PL}$ & Production & Production & \\
\hline & Value & Reallocation & worker & worker & Capital \\
\hline & Added & $\left(\mathrm{PL} \_\mathrm{RE}\right)$ & "gap" term & "gap" term & "gap" term \\
\hline 1977 & 5.4 & 1.2 & 0.4 & -0.1 & 0.1 \\
\hline 1978 & 5.0 & 1.8 & 1.0 & 0.5 & 0.2 \\
\hline 1979 & 4.4 & 0.8 & 0.1 & 0.5 & 0.3 \\
\hline 1980 & -4.6 & -0.6 & -1.8 & 0.4 & 0.8 \\
\hline 1981 & 2.5 & 0.7 & -0.2 & 0.1 & 0.8 \\
\hline 1982 & -6.0 & -2.5 & -3.0 & -0.1 & 0.6 \\
\hline 1983 & 5.8 & 0.1 & -0.3 & -0.2 & 0.6 \\
\hline 1984 & 4.4 & 1.6 & 1.0 & 0.1 & 0.5 \\
\hline 1985 & 3.4 & 1.3 & -0.2 & 0.3 & 1.2 \\
\hline 1986 & 0.3 & 0.9 & -0.4 & 0.1 & 1.2 \\
\hline 1987 & 5.4 & 0.8 & 0.1 & -0.1 & 0.8 \\
\hline 1988 & 4.5 & 1.3 & 0.6 & 0.1 & 0.6 \\
\hline 1989 & -0.2 & 0.6 & 0.0 & 0.0 & 0.6 \\
\hline 1990 & -2.1 & 0.4 & -1.0 & 0.1 & 1.3 \\
\hline 1991 & -1.1 & 0.3 & -0.9 & 0.1 & 1.1 \\
\hline 1992 & 2.7 & 0.9 & 0.0 & -0.4 & 1.2 \\
\hline 1993 & 1.6 & 0.7 & -0.3 & -0.2 & 1.2 \\
\hline 1994 & 4.3 & 0.8 & 0.3 & -0.3 & 0.9 \\
\hline 1995 & 5.2 & 2.1 & 0.2 & 0.5 & 1.4 \\
\hline 1996 & 2.6 & 1.9 & 0.1 & 0.2 & 1.6 \\
\hline 1997 & 8.4 & 1.7 & 0.3 & 0.4 & 1.0 \\
\hline 1998 & 5.8 & 1.0 & -0.7 & 0.1 & 1.6 \\
\hline 1999 & 4.7 & 0.9 & -0.1 & 0.0 & 1.0 \\
\hline mean & 2.7 & 0.8 & -0.2 & 0.1 & 0.9 \\
\hline s.d. & 3.5 & 1.0 & 0.9 & 0.3 & 0.4 \\
\hline
\end{tabular}

Value-added Production functions estimated by OLS 
Table A7: Percentage Growth Rates of Real Value-Added in U.S. Manufacturing, 1977-1996

\begin{tabular}{|c|c|c|c|c|c|}
\hline Year & $\begin{array}{c}\text { (1) } \\
\text { All } \\
\text { ASM } \\
\text { plants, } \\
\text { Aggregates }\end{array}$ & $\begin{array}{c}(2) \\
\text { Continuers } \\
\text { in estimation } \\
\text { sample, } \\
\text { Aggregates }\end{array}$ & $\begin{array}{c}(3) \\
\text { Continuers }+ \\
\text { "false" entrants } \\
\& \text { exits in } \\
\text { estimation sample, } \\
\text { Aggregates }\end{array}$ & $\begin{array}{c}\text { (4) } \\
\text { Entire } \\
\text { estimation } \\
\text { sample, } \\
\text { Aggregates }\end{array}$ & $\begin{array}{c}(5) \\
\text { Continuers } \\
\text { in estimation } \\
\text { sample, } \\
\text { Tornqvist } \\
\text { index }\end{array}$ \\
\hline 1977 & 6.1 & 4.9 & 5.4 & 6.9 & 6.2 \\
\hline 1978 & 4.7 & 4.8 & 4.1 & 4.4 & 5.5 \\
\hline 1979 & 3.3 & 8.7 & 4.5 & 4.1 & 6.4 \\
\hline 1980 & -6.0 & -5.8 & -10.4 & -10.5 & -6.2 \\
\hline 1981 & 0.8 & 0.3 & 3.9 & 3.8 & 2.7 \\
\hline 1982 & -7.2 & -8.0 & -7.4 & -7.4 & -8.0 \\
\hline 1983 & 3.1 & 5.0 & 3.8 & 3.2 & 5.9 \\
\hline 1984 & 11.0 & 5.1 & 11.3 & 11.3 & 8.6 \\
\hline 1985 & -0.3 & 0.6 & 0.0 & -0.3 & 0.5 \\
\hline 1986 & -0.3 & -0.4 & -0.1 & -0.6 & -0.3 \\
\hline 1987 & 7.0 & 6.2 & 7.5 & 7.1 & 6.7 \\
\hline 1988 & 4.0 & 4.7 & 3.2 & 3.5 & 5.1 \\
\hline 1989 & 4.5 & 0.2 & 3.2 & 4.0 & -0.7 \\
\hline 1990 & -1.5 & -1.7 & -2.1 & -1.8 & -3.1 \\
\hline 1991 & -3.9 & -2.4 & -3.3 & -3.5 & -2.5 \\
\hline 1992 & 9.9 & 4.2 & 10.6 & 10.4 & 3.4 \\
\hline 1993 & -1.4 & -1.4 & -2.1 & -2.1 & 1.9 \\
\hline 1994 & 11.7 & 11.0 & 12.0 & 11.5 & 6.9 \\
\hline 1995 & 12.0 & 11.6 & 10.5 & 12.1 & 4.7 \\
\hline 1996 & 12.5 & 13.4 & 12.2 & 12.1 & 2.9 \\
\hline Mean & 3.5 & 3.0 & 3.3 & 3.4 & 2.3 \\
\hline std. dev. & 6.0 & 5.7 & 6.4 & 6.5 & 4.6 \\
\hline
\end{tabular}


Table A8: Fixed Costs Term and Discrete-time Approximation Error, 1977-1996

\begin{tabular}{|c|c|c|c|}
\hline Year & $\begin{array}{c}(1) \\
\text { "Fixed Costs" term } \\
\text { (see equation } 16 \text { ) } \\
\% \text { growth rate }\end{array}$ & $\begin{array}{c}(2) \\
\text { Approximation error } \\
\text { (RHS of equation } 46 \text { ) }\end{array}$ & $\begin{array}{c}(3) \\
\text { Difference } \\
(1)-(2)\end{array}$ \\
\hline 1977 & -0.27 & -0.24 & -0.03 \\
\hline 1978 & -0.23 & -0.18 & -0.05 \\
\hline 1979 & -1.29 & -1.30 & 0.00 \\
\hline 1980 & 0.93 & 0.94 & -0.01 \\
\hline 1981 & -1.45 & -1.48 & 0.03 \\
\hline 1982 & 0.22 & 0.11 & 0.10 \\
\hline 1983 & -0.11 & -0.11 & 0.00 \\
\hline 1984 & -0.08 & -0.05 & -0.02 \\
\hline 1985 & -0.36 & -0.37 & 0.01 \\
\hline 1986 & -0.18 & -0.14 & -0.03 \\
\hline 1987 & -0.67 & -0.65 & -0.02 \\
\hline 1988 & -0.01 & 0.01 & -0.02 \\
\hline 1989 & 0.24 & 0.23 & 0.01 \\
\hline 1990 & 0.93 & 0.60 & 0.32 \\
\hline 1991 & 1.22 & 0.51 & 0.71 \\
\hline 1992 & 0.50 & 0.50 & 0.00 \\
\hline 1993 & 0.74 & 0.77 & -0.03 \\
\hline 1994 & 0.40 & 0.40 & 0.00 \\
\hline 1995 & 0.41 & 0.44 & -0.03 \\
\hline 1996 & 1.28 & 1.28 & 0.00 \\
\hline Mean & 0.11 & 0.06 & 0.05 \\
\hline std. dev. & 0.74 & 0.68 & 0.17 \\
\hline
\end{tabular}

Source: Annual Survey of Manufactures

Gross Output Production Functions estimated by Wooldridge (2005) modification of Levinsohn and Petrin (2003) estimator. 
Table A9: Aggregate Productivity Growth and Technical Efficiency Growth Production Workers vs. Production Worker Hours, 1977-1996

\begin{tabular}{|c|c|c|c|c|c|c|}
\hline \multirow[b]{2}{*}{ Year } & \multicolumn{6}{|c|}{ Percentage Growth Rates of ... } \\
\hline & $\begin{array}{c}1(1) \\
\text { PL Aggregate } \\
\text { Productivity, } \\
\text { using number } \\
\text { of production } \\
\text { workers } \\
\end{array}$ & $\begin{array}{c}(2) \\
\text { PL Aggregate } \\
\text { Productivity, } \\
\text { using } \\
\text { production } \\
\text { worker hours } \\
\end{array}$ & $\begin{array}{c}(3) \\
\text { Difference } \\
(1)-(2)\end{array}$ & $\begin{array}{c}(4) \\
\text { Technical } \\
\text { Efficiency, } \\
\text { using number } \\
\text { production } \\
\text { workers } \\
\end{array}$ & $\begin{array}{c}(5) \\
\text { Technical } \\
\text { Efficiency, } \\
\text { using } \\
\text { production } \\
\text { worker hours }\end{array}$ & $\begin{array}{c}(6) \\
\text { Difference } \\
(4)-(5)\end{array}$ \\
\hline 1977 & 4.5 & 4.3 & 0.2 & 1.2 & 0.8 & 0.4 \\
\hline 1978 & 3.6 & 3.6 & 0.0 & 0.4 & 0.4 & 0.0 \\
\hline 1979 & 5.1 & 5.4 & -0.2 & 1.0 & 1.4 & -0.4 \\
\hline 1980 & -5.5 & -5.1 & -0.4 & -6.1 & -5.3 & -0.8 \\
\hline 1981 & 2.9 & 2.8 & 0.1 & 0.2 & 0.1 & 0.1 \\
\hline 1982 & -5.2 & -4.5 & -0.7 & -5.2 & -4.1 & -1.1 \\
\hline 1983 & 6.5 & 5.9 & 0.5 & 5.7 & 4.8 & 0.9 \\
\hline 1984 & 7.2 & 6.8 & 0.4 & 3.9 & 3.3 & 0.6 \\
\hline 1985 & 0.3 & 0.3 & -0.1 & -2.5 & -2.4 & -0.1 \\
\hline 1986 & -0.1 & -0.3 & 0.2 & -2.2 & -2.4 & 0.1 \\
\hline 1987 & 6.8 & 6.7 & 0.1 & 4.3 & 4.1 & 0.2 \\
\hline 1988 & 4.5 & 4.4 & 0.1 & 2.6 & 2.4 & 0.2 \\
\hline 1989 & -0.9 & -0.9 & 0.0 & -2.2 & -2.1 & -0.1 \\
\hline 1990 & -2.6 & -2.5 & -0.1 & -2.6 & -2.4 & -0.2 \\
\hline 1991 & -2.0 & -2.0 & 0.0 & -2.1 & -2.0 & -0.1 \\
\hline 1992 & 3.8 & 3.7 & 0.1 & 2.9 & 2.7 & 0.2 \\
\hline 1993 & 2.1 & 1.9 & 0.2 & 1.5 & 1.3 & 0.2 \\
\hline 1994 & 6.7 & 6.5 & 0.2 & 5.5 & 5.1 & 0.4 \\
\hline 1995 & 4.0 & 4.2 & -0.2 & 1.8 & 2.1 & -0.3 \\
\hline 1996 & 2.6 & 2.5 & 0.1 & 1.0 & 0.7 & 0.2 \\
\hline Mean & 2.2 & 2.2 & 0.0 & 0.4 & 0.4 & 0.0 \\
\hline std. dev. & 3.9 & 3.7 & 0.3 & 3.3 & 3.0 & 0.5 \\
\hline
\end{tabular}

Gross Output Production Functions estimated by Levinsohn and Petrin (2003) estimator. 
Table A10a: Aggregate Productivity Growth Decomposition Baily, Hulten, \& Campbell vs. Petrin-Levinsohn. U.S. Manufacturing 1977-1996

\begin{tabular}{|c|c|c|c|c|c|c|}
\hline \multirow[b]{6}{*}{ Year } & \multicolumn{6}{|c|}{ Percentage Growth Rates of ... } \\
\hline & & & \multicolumn{2}{|c|}{$\mathrm{PL} \_\mathrm{APG}=\mathrm{TE}+\mathrm{PL} \_\mathrm{RE}$} & \multicolumn{2}{|c|}{$\mathrm{BHC}=\mathrm{TE}+\mathrm{BHC} \_\mathrm{RE}$} \\
\hline & $(1)$ & $(2)$ & (3) & $(4)$ & $(5)$ & (6) \\
\hline & & PL Aggregate & Technical & PL & BHC Productivity & $\mathrm{BHC}$ \\
\hline & Value & Productivity & Efficiency & Reallocation & Index & Reallocation \\
\hline & Added & (PL_APG) & $(\mathrm{TE})$ & (PL_RE) & (BHC) & (BHC_RE) \\
\hline 1977 & 6.2 & 4.3 & 0.8 & 3.5 & 1.4 & 0.5 \\
\hline 1978 & 5.5 & 3.6 & 0.3 & 3.2 & 1.3 & 0.9 \\
\hline 1979 & 6.4 & 5.4 & 1.3 & 4.0 & 3.4 & 2.0 \\
\hline 1980 & -6.2 & -5.1 & -5.3 & 0.2 & 3.1 & 8.5 \\
\hline 1981 & 2.7 & 2.8 & -0.1 & 2.7 & 3.4 & 3.3 \\
\hline 1982 & -8.0 & -4.5 & -4.1 & -0.4 & -21.0 & -16.6 \\
\hline 1983 & 5.9 & 5.9 & 4.8 & 1.1 & -2.6 & -7.4 \\
\hline 1984 & 8.6 & 6.8 & 3.3 & 3.6 & -0.2 & -3.4 \\
\hline 1985 & 0.5 & 0.3 & -2.4 & 2.8 & -9.1 & -6.7 \\
\hline 1986 & -0.3 & -0.2 & -2.4 & 2.1 & -20.3 & -18.0 \\
\hline 1987 & 6.7 & 6.7 & 4.1 & 2.6 & 0.5 & -3.6 \\
\hline 1988 & 5.1 & 4.4 & 2.4 & 2.1 & 5.8 & 3.4 \\
\hline 1989 & -0.7 & -0.9 & -2.1 & 1.2 & 2.3 & 4.3 \\
\hline 1990 & -3.1 & -2.5 & -2.4 & -0.0 & 0.9 & 3.4 \\
\hline 1991 & -2.5 & -2.0 & -2.0 & 0.0 & -9.9 & -7.9 \\
\hline 1992 & 3.4 & 3.7 & 2.7 & 1.0 & -7.0 & -9.7 \\
\hline 1993 & 1.9 & 1.9 & 1.3 & 0.6 & 6.8 & 5.5 \\
\hline 1994 & 6.9 & 6.5 & 5.1 & 1.4 & 1.8 & -3.2 \\
\hline 1995 & 4.7 & 4.2 & 2.1 & 2.1 & 6.5 & 4.6 \\
\hline 1996 & 2.9 & 2.5 & 0.7 & 1.7 & 6.0 & 5.3 \\
\hline Mean & 2.3 & 2.2 & 0.4 & 1.8 & -1.3 & -1.7 \\
\hline s.d. & 4.6 & 3.7 & 3.0 & 1.3 & 8.1 & 7.4 \\
\hline
\end{tabular}

Gross Output Production Functions estimated by Levinsohn and Petrin (2003) estimator.

Correlations of Annual Growth Rates

\begin{tabular}{lcc}
\hline & PL_APG & TE \\
TE & 0.95 & \\
BHC Index & 0.43 & 0.41
\end{tabular}


Table A10b: Aggregate Productivity Growth Decomposition Baily, Hulten, \& Campbell vs. Petrin-Levinsohn. U.S. Manufacturing 1977-1996

\begin{tabular}{|c|c|c|c|c|c|c|}
\hline \multirow[b]{6}{*}{ Year } & \multicolumn{6}{|c|}{ Percentage Growth Rates of ... } \\
\hline & & & \multicolumn{2}{|c|}{$\mathrm{PL} \_\mathrm{APG}=\mathrm{TE}+\mathrm{PL} \_\mathrm{RE}$} & \multicolumn{2}{|c|}{$\mathrm{BHC}=\mathrm{TE}+\mathrm{BHC} \_\mathrm{RE}$} \\
\hline & $(1)$ & $(2)$ & $(3)$ & $(4)$ & $(5)$ & $(6)$ \\
\hline & & PL Aggregate & Technical & PL & BHC Productivity & $\mathrm{BHC}$ \\
\hline & Value & Productivity & Efficiency & Reallocation & Index & Reallocation \\
\hline & Added & (PL_APG) & $(\mathrm{TE})$ & (PL_RE) & $(\mathrm{BHC})$ & (BHC_RE) \\
\hline 1977 & 6.2 & 4.3 & 0.6 & 3.7 & 2.7 & 2.1 \\
\hline 1978 & 5.5 & 3.6 & 0.5 & 3.1 & 2.4 & 1.9 \\
\hline 1979 & 6.4 & 5.4 & 2.0 & 3.4 & 4.4 & 2.4 \\
\hline 1980 & -6.2 & -5.1 & -3.9 & -1.2 & 3.8 & 7.8 \\
\hline 1981 & 2.7 & 2.8 & -0.3 & 3.1 & 1.3 & 1.6 \\
\hline 1982 & -8.0 & -4.5 & -3.0 & -1.5 & -14.3 & -11.3 \\
\hline 1983 & 5.9 & 5.9 & 4.4 & 1.5 & -1.5 & -5.9 \\
\hline 1984 & 8.6 & 6.8 & 2.4 & 4.4 & 1.2 & -1.2 \\
\hline 1985 & 0.5 & 0.3 & -2.0 & 2.3 & -4.7 & -2.8 \\
\hline 1986 & -0.3 & -0.2 & -2.3 & 2.0 & -15.3 & -13.0 \\
\hline 1987 & 6.7 & 6.7 & 4.2 & 2.4 & 0.1 & -4.2 \\
\hline 1988 & 5.1 & 4.4 & 1.9 & 2.5 & 4.0 & 2.1 \\
\hline 1989 & -0.7 & -0.9 & -1.7 & 0.8 & 1.4 & 3.1 \\
\hline 1990 & -3.1 & -2.5 & -1.4 & -1.1 & 0.5 & 2.0 \\
\hline 1991 & -2.5 & -2.0 & -1.5 & -0.5 & -6.3 & -4.9 \\
\hline 1992 & 3.4 & 3.7 & 2.9 & 0.8 & -4.0 & -7.0 \\
\hline 1993 & 1.9 & 1.9 & 1.3 & 0.6 & 6.6 & 5.4 \\
\hline 1994 & 6.9 & 6.5 & 4.7 & 1.8 & 2.3 & -2.4 \\
\hline 1995 & 4.7 & 4.2 & 2.4 & 1.8 & 6.1 & 3.7 \\
\hline 1996 & 2.9 & 2.5 & 1.6 & 0.9 & 8.7 & 7.2 \\
\hline Mean & 2.3 & 2.2 & 0.6 & 1.6 & -0.0 & -0.7 \\
\hline s.d. & 4.6 & 3.7 & 2.6 & 1.7 & 6.3 & 5.7 \\
\hline
\end{tabular}

Gross Output Production Functions estimated by $O L S$.

Correlations of Annual Growth Rates

$\begin{array}{lcc} & \text { PL_APG } & \text { TE } \\ \text { TE } & 0.92 & \\ \text { BHC Index } & 0.42 & 0.43\end{array}$


Table A10c: Aggregate Productivity Growth Decomposition Baily, Hulten, \& Campbell vs. Petrin-Levinsohn. U.S. Manufacturing 1977-1996

\begin{tabular}{|c|c|c|c|c|c|c|}
\hline \multirow[b]{6}{*}{ Year } & \multicolumn{6}{|c|}{ Percentage Growth Rates of ... } \\
\hline & & & \multicolumn{2}{|c|}{$\mathrm{PL} \_\mathrm{APG}=\mathrm{TE}+\mathrm{PL} \_\mathrm{RE}$} & \multicolumn{2}{|c|}{$\mathrm{BHC}=\mathrm{TE}+\mathrm{BHC} \_\mathrm{RE}$} \\
\hline & (1) & $(2)$ & $(3)$ & $(4)$ & (5) & $(6)$ \\
\hline & & PL Aggregate & Technical & $\mathrm{PL}$ & BHC Productivity & $\mathrm{BHC}$ \\
\hline & Value & Productivity & Efficiency & Reallocation & Index & Reallocation \\
\hline & Added & (PL_APG) & $(\mathrm{TE})$ & (PL_RE) & $(\mathrm{BHC})$ & (BHC_RE) \\
\hline 1977 & 6.2 & 4.3 & -0.5 & 4.8 & -3.5 & -3.0 \\
\hline 1978 & 5.5 & 3.6 & 1.0 & 2.6 & 1.4 & 0.4 \\
\hline 1979 & 6.4 & 5.4 & 3.1 & 2.3 & 4.4 & 1.3 \\
\hline 1980 & -6.2 & -5.1 & -3.9 & -1.2 & 10.0 & 14.0 \\
\hline 1981 & 2.7 & 2.8 & -0.1 & 2.9 & 1.4 & 1.4 \\
\hline 1982 & -8.0 & -4.5 & -2.9 & -1.6 & -0.4 & 2.5 \\
\hline 1983 & 5.9 & 5.9 & 4.2 & 1.8 & -5.1 & -9.3 \\
\hline 1984 & 8.6 & 6.8 & 1.9 & 4.9 & -3.9 & -5.8 \\
\hline 1985 & 0.5 & 0.3 & -3.5 & 3.8 & -3.1 & 0.4 \\
\hline 1986 & -0.3 & -0.2 & -4.3 & 4.0 & -13.7 & -9.4 \\
\hline 1987 & 6.7 & 6.7 & 3.1 & 3.6 & 6.2 & 3.1 \\
\hline 1988 & 5.1 & 4.4 & 2.1 & 2.4 & 11.5 & 9.5 \\
\hline 1989 & -0.7 & -0.9 & -2.3 & 1.4 & 3.3 & 5.6 \\
\hline 1990 & -3.1 & -2.5 & -0.4 & -2.1 & -9.1 & -8.7 \\
\hline 1991 & -2.5 & -2.0 & -2.7 & -0.7 & -1.0 & 1.7 \\
\hline 1992 & 3.4 & 3.7 & 3.0 & 0.7 & 5.5 & 2.5 \\
\hline 1993 & 1.9 & 1.9 & 0.1 & 1.8 & -20.3 & -20.4 \\
\hline 1994 & 6.9 & 6.5 & 3.9 & 2.6 & 2.3 & -1.6 \\
\hline 1995 & 4.7 & 4.2 & 2.2 & 2.0 & 10.2 & 8.0 \\
\hline 1996 & 2.9 & 2.5 & 0.6 & 1.9 & 5.4 & 4.9 \\
\hline Mean & 2.3 & 2.2 & 0.2 & 2.0 & 0.1 & -0.1 \\
\hline s.d. & 4.6 & 3.7 & 2.7 & 1.9 & 8.0 & 7.8 \\
\hline
\end{tabular}

Gross Output Production Functions estimated by Wooldridge (2005) modification of

Levinsohn and Petrin (2003) estimator.

Correlations of Annual Growth Rates

\begin{tabular}{lcc}
\hline & PL_APG & TE \\
TE & 0.86 & \\
BHC Index & 0.14 & 0.27
\end{tabular}

